\title{
CONCEPTO DE PERSONA, TITULARIDAD DEL DERECHO A LA VIDA Y ABORTO
}

\author{
Rodolfo Figueroa García-Huidobro*
}

\begin{abstract}
RESUMEN
Para la mayoría de la doctrina nacional, el concepto de persona es equivalente a ser humano desde el momento de la concepción y, por ende, el ser humano desde la concepción es titular del derecho a la vida. Sin embargo, no hay razones constitucionales para sostener esa postura. Los derechos constitucionales se confieren a las personas y en ausencia de definición constitucional de persona, ha de aplicarse la legal, según la cual la existencia legal de la persona principia al nacer. Este es, por lo demás, el criterio imperante en la jurisprudencia comparada e internacional, la que nunca ha sostenido que el ser humano sea persona desde la concepción. Sin embargo, esto no significa que el ser humano antes de nacer esté desprovisto de protección; la ley debe brindar esa protección, pero hacerlo no significa transformarlo en titular del derecho a la vida. Proteger la vida del que está por nacer y permitir el aborto son actos compatibles, como lo muestra toda la jurisprudencia constitucional comparada que se ba pronunciado sobre este asunto.
\end{abstract}

PERSONA - DERECHO A LA VIDA - ABORTO

\section{Concept of person, entitlement to the right to life and abortion}

\begin{abstract}
For the majority or our legal community, the legal concept of natural person is equivalent to that of human being from the moment of conception and, therefore, from that moment a person is entitled to the right to life. However, there is no constitutional basis for sustaining that opinion. Foreign and International have never affirmed that a human being is a legally person from the moment of conception. That does not mean that a buman being is unprotected before being born. The law must provide that protection, but doing so does not mean entitling a buman being to the right to life. Only in the German case the nasciturus is entitled to such a right, although at the same time abortion is permitted. In the end, protecting the life of the unborn and allowing abortion are compatible positions, as demonstrated by all the constitutional case law that has been passed on this matter.
\end{abstract}

\section{NATURAL PERSON- RIGHT TO LIFE - ABORTION}

* Abogado, Máster en Derecho, Profesor de Derecho Constitucional, Escuela de Derecho, Universidad Diego Portales, República No 105, Santiago de Chile, rodolfo.figueroa@udp.cl Trabajo recibido el 25 de abril de 2007 y aceptado para su publicación por el Comité Editorial el 22 de octubre de 2007. 


\section{INTRODUCCIÓN}

1. El objetivo de este trabajo es analizar el concepto de persona para efectos del derecho constitucional. Este concepto es fundamental pues determina la tituresulta importante para la discusión sobre el aborto. La metodología será revisar lo que ha señalado la doctrina nacional y considerar luego los desarrollos de la jurisprudencia nacional, comparada e internacional.

En Chile, los titulares del derecho a la vida, al igual que respecto de los demás derechos, están señalados por el encabezado ${ }^{1}$ del artículo 19 de la Constitución: son las personas. Por ello, la pregunta a examinar es qué debe entenderse por persona. En aquellos países en que el titular del derecho a la vida no es una persona (Alemania) o en aquellos que protegen la vida sin requerir un titular (Colombia, España), ${ }^{2}$ la pregunta no es relevante.

2. La palabra persona en las normas jurídicas

La palabra persona no se encuentra definida por la Constitución aunque sí por la ley. El artículo 55 del Código Civil, aludiendo a la persona natural, la define así: "Son personas todos los individuos de la especie humana, cualquiera que sea su edad, sexo, extirpe o condición (sic)." Luego, el Código Civil presenta un Título II relativo al principio y fin de la existencia de las personas naturales. En el párrafo 1, el artículo 74 se refiere a la existencia legal de la persona: "La existencia legal de toda persona principia al nacer, esto es, al separarse completamente de la madre." Por tanto, antes de nacer no existe legalmente una persona. Agrega el mismo artículo 74: "La criatura que muere en el vientre materno, o que perece antes de estar completamente separada de su madre, o que no haya sobrevivido a la separación un momento siquiera, se reputará no haber existido jamás." Así pues, no queda duda que antes de nacer, el ser humano no es ni ha sido persona para efectos legales. Esto no impide que se pueda proteger la vida del nasciturus. Lo dice el artículo 75: la ley protege la vida del que está por nacer y el juez puede adoptar todas las providencias que juzgue pertinentes para proteger la existencia del no nacido siempre que crea que de algún modo peligra. Incluso, la ley confiere al no nacido derechos sucesorios suspensivos, condicionados al nacimiento y sobrevivencia un momento siquiera (de otro modo, los derechos pasarán a otras personas como si la criatura no hubiese jamás existido, artículo 77). Sin embargo, nacer y sobrevivir un momento siquiera es un requisito indispensable para ser persona legal. Por tanto, sólo son legalmente personas para el Código Civil: a) seres humanos y b) que hayan nacido.

Estando definida la voz persona por la ley pero no por la Constitución, disponemos de dos opciones si deseamos manejar un concepto de persona para efectos constitucio-

${ }^{1}$ Hay constituciones que siguen otro sistema: no señalan un titular genérico para todos los derechos sino que emplean diversas expresiones a propósito de diversos derechos (España, Alemania). Lo veremos más adelante.

${ }^{2}$ Aunque también protegen el derecho a la vida. 
nales: recurrir a la definición que contempla el Código Civil o desatender la definición legal y construir un concepto ad-hoc de persona. En la práctica, esta segunda opción se traduce en modificar el $2^{\circ}$ elemento de la definición (no el primero), ${ }^{3}$ sustituyendo nacimiento por concepción. Por tanto, las opciones son: son personas los seres humanos desde la concepción o desde el nacimiento.

\section{EL CONCEPTO DE PERSONA EN LA DOCTRINA NACIONAL}

En esta sección, voy a presentar la posición de la doctrina nacional sobre el concepto de persona. No formularé comentarios críticos, que se dejan para más adelante.

1. El concepto de persona no ha sido objeto de mayor discusión por parte de la doctrina. Parece existir bastante consenso en la mayoría de los autores nacionales en torno a una serie de puntos, que se exponen a continuación:

1.1. En primer lugar, la mayoría de los autores entiende que es persona el ser humano desde el momento de la concepción o fecundación. Esto significa que estiman como sinónimos las expresiones persona y ser humano (obviamente, desde la concepción). Por ejemplo, un autor alude a varios principios; uno de ellos es "la protección de la vida y de la dignidad de las persona humana." ${ }^{4}$ Luego, se refiere a ese principio como "[E]l principio de protección a la vida humana y a la dignidad del hombre..." 5 Se puede apreciar que las expresiones "persona humana", "vida humana" y "hombre" son consideradas equivalentes. Otro autor sostiene que el concepto jurídico de persona, definido por el art. 55 del Código Civil, se corresponde con el que él llama filosófico, fundado en el Evangelio de Jesucristo; ${ }^{6}$ todo ser humano es persona, ${ }^{7}$ ambos conceptos no pueden separarse ${ }^{8}$. Otro ejemplo en que se aprecia esta sinonimia entre persona y ser humano es el siguiente: "El derecho a la vida representa, entonces, la facultad jurí-

${ }^{3}$ En efecto, en Chile ningún comentarista de la Constitución ha sugerido adherir al concepto de persona de Peter Singer. Para este autor, son personas los seres racionales y autoconscientes (p. 101, 110), en cuanto entidades separadas, con pasado y futuro (p. 122). Esta concepción de Singer tiene como consecuencia que algunos seres humanos nacidos no son personas y algunos animales no humanos sí lo son (conjeturalmente -dice Singer, p. 127- pueden serlo chimpancés, ballenas, delfines, perros, gatos, cerdos). Por tanto, para Singer el eje está puesto en el primer elemento la noción de persona (que se exija sea humana), y no en el segundo (que haya nacido. De hecho, para Singer, el nacimiento por sí solo no es indicativo de personalidad moral, como es obvio). Ver Singer, P., Ética Práctica. Ariel. Traducción de Marta Guastavino. $2^{a}$ edición, Barcelona, 1988. Sin embargo, en la doctrina civil, Gonzalo Figueroa constituye una excepción en la medida en que considera que la titularidad de derechos no se limita a los seres humanos.

${ }^{4}$ Corral, H., "Admisibilidad jurídica de las técnicas de procreación artificial”. En Revista Chilena de Derecho, Vol. 19, 1992. p. 447.

5 Corral, ibid., p. 449.

${ }^{6}$ Zapata, P., "Persona y embrión humano. Nuevo problemas legales y su solución en el derecho chileno". En Revista Chilena de Derecho, Vol. 15, 1988, p. 376.

7 Zapata, ibid., p. 376.

8 Zapata, ibid. p. 378. 
dica, o poder, de exigir la conservación y la protección de la vida humana, o sea, de ese estado de actividad sustancial propio del hombre." ${ }^{9}$ Se suma a lo anterior el siguiente: "[T]odo ser humano tiene el derecho esencial de conservar su vida." 10 Otro autor lo pone de este modo: “...el sujeto biológico denominado hombre, comienza con la fecundación”. ${ }^{11} \mathrm{El}$ derecho a la vida es el derecho que tienen los hombres ${ }^{12}$. En cuanto al concepto de persona, este autor sostiene que es un concepto filosófico y puntualiza que, en ese contexto, el embrión es persona desde que tiene alma humana, y tiene alma humana desde la concepción. ${ }^{13}$ Otro comentarista apunta: “...se debe concluir que desde la fecundación estamos en presencia de una persona humana." 14 Otro autor de modo sorprendente afirma: “... aun cuando no expresa la Constitución -como decíamos- una noción de persona, sin embargo se encarga muy precisamente de reconocer que quien está por nacer es una persona; en otros términos, la criatura humana que está en el vientre materno es una persona." 15 Una última referencia “...el ser humano en el seno materno es, desde su concepción, sujeto de derechos fundamentales y que deben serle respetados, comenzando por la vida." 16

Podemos cerrar esta parte señalando que estos autores optan por no seguir la noción de persona del Código Civil. ${ }^{17}$

1.2. En segundo lugar, la doctrina no suele estimar necesario ahondar en una definición de la palabra persona. Hay un autor que sí lo hace: después de algunas consideraciones históricas, filosóficas y jurídicas, propone su concepto de persona: “...la persona para el derecho es, en suma, aquel ser inteligente y libre que ostenta un dominio sobre sí mismo y sobre sus actos, en cuanto es considerado protagonista esencial de la vida del

${ }^{9}$ Verdugo, M. et al., Derecho Constitucional. Editorial Jurídica de Chile. Segunda Edición, Santiago, 2005, p. 199.

${ }^{10}$ Frase dicha cuando se explica el derecho a la vida. Evans, E. Los Derechos Constitucionales, Editorial Jurídica de Chile, $3^{\text {a }}$ edición, Santiago, 2004, p. 113.

11 Ugarte, J., El Derecho de la vida. Editorial Jurídica de Chile, Santiago, 2006, p. 235. Cursiva en el original.

12 Ugarte, ibid., pp. 117 ss.

13 Ugarte, ibíd., p. 258. El mismo autor, antes y en el mismo sentido, en "Momento en que el embrión es persona humana”, en Estudios Públicos, 96 (primavera), Santiago, 2004.

14 Silva, J., "El nasciturus y el derecho a la vida", en Revista de Derecho Público, nº 57/58, enero-diciembre, Santiago, 1995, p. 186. En sentido similar opina Varela, en Varela J. “Derechos Humanos y Aborto”, en Revista de Derecho Público, $\mathrm{n}^{\circ} \mathrm{s} 47 / 48$, enero-diciembre, Santiago, 1990, p. 197. Opina lo mismo Vivanco, en Vivanco, A. Curso de Derecho Constitucional. Ediciones Universidad Católica de Chile. Santiago, 2006, p. 244.

15 Soto, E., "La noción de persona en la Constitución", en Revista de Derecho Público, N 50, juliodiciembre, Santiago, 1991, p. 139. Lo mismo piensa Fermandois, en Fermandois, A. "La píldora del día después: aspectos normativos”, en Estudios Públicos, 95 (invierno), Santiago, 2004, p. 101.

16 Cea, J., Derecho Constitucional Chileno, Tomo II, Ediciones Universidad Católica de Chile, Santiago, 2004 , p. 46.

17 Ángela Vivanco es explícita en este punto. En efecto, en su libro contiene una sección e.2) titulada: "Inconveniencia de aplicar al no nacido el concepto de persona del Código Civil chileno. Ob. cit., pp. 254 y ss. 
derecho y centro en torno al cual se construye y estructura el ordenamiento jurídico. En pocas palabras: el ser humano mirado desde el prisma jurídico." 18

1.3. En tercer lugar, los seres humanos son sujetos de protección constitucional. ${ }^{19}$

1.4. En cuarto lugar, el ser humano desde la concepción es titular del derecho a la vida, ${ }^{20}$ lo que es distinto del punto 3). Esto significa que el preembrión y un ser humano nacido gozan de la misma protección desde un punto de vista constitucional, ${ }^{21}$ conforme la postura mayoritaria de la doctrina nacional.

1.5. Lo anterior implica, en quinto lugar, que el aborto debe entenderse prohibido siempre, ${ }^{22}$ aunque no todos lo afirman así de categórico. ${ }^{23}$

${ }^{18}$ Corral, H., "El concepto jurídico de persona. Una propuesta de reconstrucción unitaria”. En Revista Chilena de Derecho, Vol. 17, 1990, p. 320.

${ }^{19}$ Por ejemplo, Corral sostiene que el embrión debe estar protegido desde la concepción porque desde ese momento hay vida humana. Ver Corral, H., "Admisibilidad jurídica de las técnicas de procreación artificial". ob. cit., p. 450. En la misma línea, Evans: [T]odo ser humano tiene el derecho esencial de conservar su vida y de exigir que el ordenamiento jurídico se la proteja contra atentados de la autoridad y de particulares". Evans, E., Los Derechos Constitucionales, ob. cit., p. 113. También Fermandois, A; ob. cit., p. 101.

${ }^{20}$ Una muestra la da Carrasco, que habla del derecho a la vida del que está por nacer. De hecho, así titula su artículo. Carrasco, S., "La garantía constitucional del derecho a la vida del que está por nacer". XVIII Jornadas Chilenas de Derecho Público. Concepción, 1987. También Silva, J., ob. cit., p. 186; también Soto, E. "Derecho a la vida y recurso de protección", Revista de Derecho y Jurisprudencia y Gaceta de los Tribunales, Tomo LXXXI, No 2, Mayo-Agosto, Santiago, 1984, Primera Parte, p. 60; también Fermandois, A., ob. cit., p. 101. Por su parte, Nogueira concuerda en que el nasciturus es sujeto de derecho y es persona. Nogueira, H. "El derecho a la vida en el ordenamiento jurídico chileno". Gaceta Jurídica, No 207, 1997, pp. 9-10.

21 Por ejemplo, Zapata, P., "Persona y embrión humano. Nuevos problemas legales y su solución en el derecho chileno”. Ob. cit., p. 382. Agrega: si la Constitución establece un mandato de proteger al que está por nacer, en el art. $19 \mathrm{~N}^{\circ} 1$, es porque el embrión es una persona que tiene derecho a la vida. p. 383, pp. 386 y ss. Otro ejemplo es Evans: [L]a vida, por ser el don primario que Dios ha dado al hombre, y por ser fuente de sus demás atributos, está cautelada por la institucionalidad constitucional y legal desde que se inicia la gestación”. Evans, ob. cit., p. 113. Otro autor dice: “...naturalmente, el nasciturus es titular de este derecho en la misma forma que lo son todas las demás personas”. Silva, J., ob. cit., p. 193. Otro autor en el mismo sentido: "[R]especto de ningún otro sujeto de derecho es posible concebir una mayor propiedad en el lenguaje que "el derecho a la vida" de la criatura que está en el vientre materno. Es ella la que por excelencia tiene un derecho adquirido a vida intrauterina desde la concepción o fecundación”. Varela, J., ob. cit., p. 197. Soto Kloss, por su parte, lo dice de manera categórica: "El que está por nacer es persona. La Constitución le asegura el derecho a la vida, como también lo asegura a quien ya ha nacido. No hay diferencia de tratamiento entre uno y otro ya que ambos son individuos de la especie humana, y sería una diferencia arbitraria, sin justificación racional pretender discriminar en cuanto al derecho a vivir, al derecho a la vida...." Soto, E., "El derecho a la vida y la noción de persona en la Constitución”. Revista de Derecho y Jurisprudencia y Gaceta de los Tribunales. Tomo LXXXVIII, N³ 3, 1991, Primera parte, p. 59.

22 Por ejemplo, Precht, J., "Consideraciones ético-jurídicas sobre el aborto terapéutico”. En Revista Chilena de Derecho, Vol. 19, 1992, pp. 516-521.

23 Un ejemplo es Evans, cuando declara que el precepto constitucional contiene “...un mandato flexible al legislador penal para no sancionar el aborto terapéutico en casos calificados...(sic). Lo que ni la ley ni la autoridad podrían autorizar o tolerar, sin infringir la Constitución, es la práctica masiva del aborto”. Evans, ob. cit., p. 114. Otro ejemplo lo dan los señores Verdugo y Pfeffer. Sostienen que “...se dejó en actas constancia de que a través del precepto constitucional se está condenando el "aborto”, y que no podría dictarse una ley que lo hiciera permisible, pero el legislador determinará si hay casos tan calificados, como el aborto terapéutico, principalmente, que puedan no ser constitutivos de delitos”. Verdugo, M. et al., Derecho 
1.6. En sexto lugar, el fundamento de esta doctrina ${ }^{24}$ habitualmente se hace residir de modo expreso en la frase "la ley protege la vida del que está por nacer" contenida en el artículo $19 \mathrm{~N}^{\circ} 1$ de la Constitución. ${ }^{25}, 26$

Como se dijo al comenzar, sobre estos puntos existe bastante consenso en la doctrina mayoritaria.

2. En una postura contraria de la recién transcrita se encuentran unos pocos autores, ${ }^{27}$ que rechazan la identidad entre los conceptos ser humano y persona, y entre embrión y persona. ${ }^{28}$ Sostienen que sólo son personas quienes han nacido. Un autor lo pone del siguiente modo: [E]s evidente que a la luz de la Constitución son personas los seres humanos nacidos." 29 Esta postura supone rechazar también el argumento de la potencialidad. ${ }^{30}$ Como consecuencia de lo anterior, estos autores suscriben la tesis de que el nasciturus carece de titularidad del derecho a la vida. ${ }^{31}$ Sin embargo, eso no significa que el nasciturus no deba ser protegido. ${ }^{32}$

Constitucional, ob. cit., p. 199 (comillas en el original). Bascuñán sostiene que esta posición de Evans y la de Verdugo y Pfeffer revelan que ellos se confunden, pues dicen algo que no se condice exactamente con la cita que hacen de las actas. Bascuñán Rodríguez, A., "La píldora del día después ante la jurisprudencia." En Estudios Públicos, 95, Santiago (invierno 2004), p. 60, nota 30.

${ }^{24}$ Es frecuente que algunos autores señalen como fundamento de que el nasciturus sea titular del derecho a la vida, el artículo $4^{\circ}$ de la Convención Americana (por ejemplo, Verdugo y Pfeffer, ob. cit., p. 200, nota 14; Cea, ob. cit., p. 47, quien le da al precepto jerarquía constitucional). Esta referencia es errónea pues el precepto dice "y en general desde la concepción”, por lo que deja en claro que será el Estado miembro el que decida la titularidad del nasciturus. Esto es aún más claro en el caso Baby Boy, de la Comisión Interamericana, que se verá más adelante.

25 Por ejemplo, Verdugo, M., et al., Derecho Constitucional, ob. cit., p. 199. También Fermandois: “...la barrera normativa inmediata que hoy impide la píldora, que es el artículo $19 \mathrm{~N}^{\circ} 1$ inciso segundo...”. Ob. cit. p. 100 .

${ }^{26}$ La separación en varias notas a pie de página tiene por finalidad ejemplificar la postura de diversos autores con casos concretos, pero todos los autores mencionados comparten en términos generales el cuerpo doctrinario sintetizado en esta parte. Bascuñán agrega otros más: Varela Del Solar, Jorge Luis: "Derechos Humanos y Aborto", ob. cit., pp. 195 y ss.; Rozas Vial, Fernando: "Problemas Jurídicos y Morales que Plantean la Inseminación Artificial y la Fecundación in Vitro”, 1989, pp. 725 y ss.; Corral Talciani, Hernán: "Comienzo de la Existencia y Personalidad del que Está por Nacer", 1989-1990, pp. 33 y ss.; Ugarte Godoy, José Joaquín: “Comienzo de la Persona Humana. Aspectos Biológico, Filosófico y Jurídico”, 2000, pp. 87 y ss.; Isler Soto, Carlos: "En Torno a la Personalidad del Embrión”, 2000, pp. 121 y ss. Ver Bascuñán, Rodríguez, A. "La píldora del día después ante la jurisprudencia”, ob. cit., p. 54 nota 8. Agrega Bascuñán, sería decisivo en esa posición el que ellos profesen la religión católica.

${ }^{27}$ Como Bascuñán y Gómez, que tienen en común que prescinden de consideraciones de carácter religioso a la hora de interpretar la Constitución, a diferencia de la gran mayoría de los autores mencionados (excluyendo a Verdugo y Pfeffer), que tienden a aludir a Dios, a la ética cristiana o derechamente a la moral católica, como se verá en la nota 80 infra.

${ }^{28}$ Bascuñán, ob. cit., p. 50 y Gómez, G., Derechos Fundamentales y Recurso de Protección, Ediciones Universidad Diego Portales, Santiago, 2005, p. 310

29 Bascuñán, ibíd., p. 49; Gómez, ibídem.

30 Bascuñán, ob. cit., pp. 49-50.

31 Gómez, ibíd., Bascuñán, ob. cit., p. 54.

32 Bascuñán, ibid. 
3. Existe una tercera postura que llega a la misma conclusión que la posición dominante, pero por otros fundamentos: sostiene que el nasciturus no es persona en el sentido técnico del Código Civil, pero es sujeto de derecho y, como tal, titular del derecho a la vida. ${ }^{33}$ El autor distingue dos conceptos: persona y sujeto de derechos. Persona corresponde al concepto técnico establecido por el Código Civil, y requiere nacimiento. En este sentido, el nasciturus no es persona. Sin embargo, el nasciturus es sujeto de derecho y en esa virtud, es titular del derecho a la vida sin ser persona. ${ }^{34}$

\section{LA NOCIÓN DE PERSONA Y TITULARIDAD DEL DERECHO A LA VIDA EN LA JURISPRUDENCIA}

\section{Jurisprudencia chilena}

\subsection{Jurisprudencia constitucional}

a) Fallo sobre recurso de protección rol 850 No 2001, de 28 de mayo de 2001

Este es el primer recurso de protección contra la píldora del día después. La Corte de Apelaciones rechazó el recurso por falta de legitimación activa. ${ }^{35}$ Sin embargo, la

33 La postura de Gonzalo Figueroa ha ido cambiando con el tiempo. En un primer texto, de 1995, Figueroa defendió una postura similar a la de Gómez y Bascuñán, al decir: "[A]ntes del nacimiento no se es persona ni sujeto de derechos...” p. 21. Más adelante, comentando el artículo 74 del Código Civil, recalca: "Antes de la separación completa de la criatura y de su sobrevivencia por un "momento siquiera", esa criatura no es persona aún” p. 43 (comillas en el original). Figueroa, G., Persona, pareja y familia, Editorial Jurídica de Chile, Santiago, 1995. En este texto existe una frase que anticipa el cambio de postura que aparecerá 6 años después: afirma que la Constitución reconoce en el artículo $19 \mathrm{~N}^{\circ} 1$ el derecho a la vida de la persona ya nacida y el derecho a la vida del que está por nacer. p. 20. En el contexto de este libro, esta frase no se entiende, porque declaró que el que está por nacer no es persona ni titular de derechos. Pero sí tiene sentido a la luz de una obra posterior, del año 2001. El autor señala ahora: “...desde el momento en que acaece (el nacimiento), el feto deviene en persona y puede ser titular activo de créditos...” p. 72 (o sea, no es persona, como había sostenido antes). Pero luego afirma: "El embrión ya implantado es titular de derechos, es sujeto de derechos, a pesar de no ser técnicamente todavía una persona.” p. 143. Más adelante agrega que conforme el art. $19 \mathrm{~N}^{\circ} 1$ inc. $2^{\circ}$ de la Constitución y el art. 75 de Código Civil, "...el nasciturus es titular del derecho a la vida" p. 145. Y finalmente, la sección 38 de su libro se titula: "el embrión implantado, como titular de derechos, es en verdad persona aunque el ordenamiento jurídico le niegue tal carácter” p. 150. Figueroa, G., Derecho Civil de la Persona Humana, Editorial Jurídica de Chile, Santiago, 2001.

34 De acuerdo con este autor, se es sujeto de derecho cuando una norma atribuye derechos. En su opinión, tanto el Código Civil como la Constitución atribuyen derechos al nasciturus. Hay que aclarar, también, que para ser un sujeto de derechos no se requiere ser un ser humano. Esta es la razón por la cual tienen sentido que este autor distinga persona de sujeto de derecho y explica que en el texto del 2001, diga que el nasciturus no es técnicamente persona pero que sí lo es en verdad (ver notas previas). Esta frase se entiende en la medida en que la palabra persona se emplea en dos sentidos: un sentido estricto, que es el técnico definido por el Código Civil, y otro sentido más amplio, que es equivalente a sujeto de derecho. El nasciturus no es persona en el primer sentido pero sí en el segundo. Esta explicación han sido proporcionada personalmente por el autor.

35 No había un sujeto recurrente individualizado, sino que se recurría por todos aquellos que estaban por nacer y sus padres. Ver $\mathrm{C}^{\circ} \mathrm{s} 8$ y 9 . 
ministra Morales presenta un voto disidente en el cual señala que debió acogerse el recurso y dejar sin efecto la resolución administrativa del ISP que autorizó el fármaco Postinal. Para la ministra disidente, el cigoto es potencialmente una persona, es decir, se acoge el argumento de la potencialidad. ${ }^{36}$ Por tanto, el ser humano es potencialmente persona desde su concepción, según este voto disidente.

b) Fallo de la Corte Suprema, rol N 2.186-2001, de 30 de agosto de 2001, dictado en apelación de la sentencia recién individualizada. Esta sentencia acoge el recurso por una serie de consideraciones. Vale la pena destacar sólo lo que es atingente a la idea de persona. La Corte Suprema señala que la pregunta relevante es “...desde cuando podemos o debemos reconocer legítima y legalmente la existencia del ser humano, más bien desde cuando corresponde otorgar protección constitucional a la existencia de la vida." ${ }^{37}$ Declara a continuación que "...el ser humano tiene derecho a la vida..."38 Luego agrega que "...se hace evidente que el que está por nacer, cualquiera sea la etapa de su desarrollo prenatal - pues la norma constitucional no distingue- tiene derecho a la vida, es decir, tiene derecho a nacer y a constituirse en persona con todos los atributos que el ordenamiento jurídico le reconoce, sin que a su respecto opere ninguna discriminación." ${ }^{39}$ Más adelante, la Corte alude al artículo 55 del Código Civil y declara: "Si entendemos que la fertilización es, como es, un proceso continuo que no resulta separable en etapas o momentos, debemos concluir que el óvulo fecundado o embrión, es ya un individuo de la especie humana y como tal, digno de protección constitucional y legal para alcanzar su pleno desarrollo hasta que el nacimiento se produzca..." 40

\subsection{Jurisprudencia chilena ordinaria}

a) Fallo de $1^{\mathrm{a}}$ instancia, del $20^{\circ}$ juzgado civil, en causa sobre nulidad de derecho público de la autorización administrativa del fármaco postinord-2, de 30 de junio de 2004, rol N $5.839-2004$.

En este fallo, que declara la nulidad, la jueza declara que “...el sujeto biológico hombre empieza con la fecundación o concepción...” y está protegido por las normas legales y constitucionales. ${ }^{41}$ No habla de persona ni utiliza el argumento de la potencialidad, sino de la realidad biológica.

b) Apelación y casación.

El fallo de apelaciones, rol 4200-03, de 10 de diciembre de 2004, recaído sobre la sentencia recién citada, y que la revoca, no formula ninguna consideración sobre el

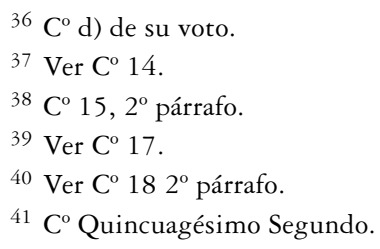


concepto de persona. En cambio, la sentencia de casación dictada por la Corte Suprema, rol 1039-2005, de 28 de noviembre de 2005, dice algo sobre el particular. En el C ${ }^{\circ} 21$, aludiendo a la legitimación activa del actor, señala que sí la tiene para propender -como cuerpo intermedio- “... a la defensa, protección, cuidado y preservación del pleno derecho a la vida desde el momento mismo de la concepción...” Esta declaración sugiere que el derecho a la vida se tiene desde la concepción. Sin embargo, en cuanto al titular del derecho, la Corte no es del todo precisa. El C 31 dispone:

"Que en esas circunstancias, la sentencia impugnada al expresar que no se demostró que el fármaco "Postinord-2" tenga los efectos abortivos que sostuvo la demanda y al desestimarla por este motivo, no ha podido transgredir las normas antes indicadas, que aseguran la vida del que está por nacer, aun aceptando que esta protección existe desde el momento de la concepción, o sea, desde la unión de un espermatozoide maduro con el óvulo constituyendo el cigoto, cuestión que no se encuentra absolutamente discernida, científicamente y jurídicamente hablando."

\section{Jurisprudencia comparada}

En esta sección revisaremos la jurisprudencia constitucional comparada que ha abordado el concepto de persona y la titularidad del derecho a la vida. Cronológicamente, se verán los fallos centrales en la materia correspondientes a EE.UU., Alemania, España y Colombia.

\subsection{Corte Suprema Federal de los EE.UU.}

La Constitución Federal de los EE.UU. establece en la Enmienda XIV que ningún estado podrá privar a ninguna persona de su vida, su libertad o su propiedad sin el debido proceso legal, ni denegar, a ninguna persona dentro de su jurisdicción, la igual protección de la ley. ${ }^{42}$ Como se puede apreciar, la Constitución Federal emplea la palabra persona. Este concepto fue objeto de análisis por parte de la jurisprudencia constitucional de los EE.UU. En efecto, la Corte Federal abordó el tema de la noción de persona en el fallo sobre aborto Roe Vs. Wade, 410 U.S. 113 (1973). ${ }^{43}$ Dice el fallo:

The Constitution does not define "person" in so many words. Section 1 of the Fourteenth Amendment contains three references to "person." The first, in defining "citizens," speaks of "persons born or naturalized in the United States." The word also appears both in the Due Process Clause and in the Equal Protection Clause. "Person"

42 “...nor shall any state deprive any person of life, liberty, or property, without due process of law; nor deny to any person within its jurisdiction the equal protection of the laws."

43 En este fallo, la Corte resolvió una impugnación de la ley de Texas que criminalizaba el aborto de manera casi absoluta. La Corte consideró que la penalización del aborto era inconstitucional, salvo si se hacía a partir de la viabilidad del feto, y siempre dejando a salvo la vida y la salud de la mujer embarazada. 
is used in other places in the Constitution: in the listing of qualifications for Representatives and Senators, Art. I, 2, cl. 2, and 3, cl. 3; in the Apportionment Clause, Art. I, 2, cl. 3;53 in the Migration and Importation provision, Art. I, 9, cl. 1; in the Emolument Clause, Art. I, 9, cl. 8; in the Electors provisions, Art. II, $1, \mathrm{cl} .2$, and the superseded cl. 3 ; in the provision outlining qualifications for the office of President, Art. II, 1, cl. 5; in the Extradition provisions, Art. IV, 2, cl. 2, and the superseded Fugitive Slave Clause 3; and in the Fifth, Twelfth, and Twenty-second Amendments, as well as in 2 and 3 of the Fourteenth Amendment. But in nearly all these instances, the use of the word is such that it has application only postnatally. None indicates, with any assurance, that it has any possible prenatal application. ${ }^{44}$

En este fallo, la Corte declara que la Constitución prácticamente no define la palabra persona y que la utiliza en diversas oportunidades, pero en todas ellas, esa palabra sólo se puede aplicar postnatalmente y con seguridad -aclara la Corte- en ningún caso tienen una aplicación prenatal. Por tanto, es exacto afirmar que la palabra persona en la jurisprudencia constitucional de los EE.UU. significa seres humanos nacidos. Eso significa que quienes no han nacido carecen de titularidad de derechos. Sin embargo, no significa que el no nacido carezca de protección por parte de la ley. Los estados pueden prohibir el aborto a partir de la viabilidad del nasciturus. ${ }^{45}$ Es importante notar que esa protección no está vinculada a titularidad de derechos sino al interés del Estado en proteger la vida humana potencial. ${ }^{46}$ Esta doctrina se ha mantenido inalterable hasta la fecha. ${ }^{47}$

44410 U.S. 113 , p. 158 . Nota pie de página $N^{\circ} 54$ en el original, eliminada.

45 Declara la Corte en la sección XI del fallo: “(c) For the stage subsequent to viability, the State in promoting its interest in the potentiality of human life [410 U.S. 113, 165] may, if it chooses, regulate, and even proscribe, abortion except where it is necessary, in appropriate medical judgment, for the preservation of the life or health of the mother."

46 En la sección X del fallo, la Corte declara: “...the State does have (...) another important and legitimate interest in protecting the potentiality of human life." Hay que recordar que en un caso de debido proceso sustantivo, que involucre a la enmienda 14, la Corte analiza y considera los intereses que pueda tener el Estado para limitar una libertad. En el caso de la ley de Texas y el aborto, uno de esos intereses es la protección de la vida humana potencial.

${ }^{47}$ En muchos casos se ha vuelto a discutir este asunto, pero en todos se ha mantenido la doctrina. Ver Doe V. Bolton, 410 U.S. 179 (1973); Planned Parenthood of Missouri v. Danforth, 428 U.S. 52 (1976), Bellotti v. Baird, 443 U.S. 622 (1979), Harris v. Mcrae, 448 U.S. 297 (1980), Thornburgh v. American Coll. of Obst. \& Gyn., 476 U.S. 747 (1986), Webster v. Reproductive Health Services, 492 U.S. 490 (1989), Hodgson v. Minnesota, 497 U.S. 417 (1990), Ohio v. Akron Center, 497 U.S. 502 (1990). El último caso federal ha sido el caso Planned Parenthood of Southeastern Pa. v. CASEY, 505 U.S. 833 (1992). Allí la Corte señala: "We conclude the line should be drawn at viability, so that, before that time, the woman has a right to choose to terminate her pregnancy." p. 871 del US Reporter..- "The woman's right to terminate her pregnancy before viability is the most central principle of Roe v. Wade. It is a rule of law and a component of liberty we cannot renounce." p. 872 del US Reporter. 


\subsection{Tribunal Constitucional Federal Alemán}

La Ley Fundamental de Bonn de 1949 reconoce el derecho a la vida en el Artículo 2 $\mathrm{N}^{\circ}$ 2. Ese precepto dispone: "Jeder hat das Recht auf Leben..." Hay traducciones hispanas que rezan "Toda persona tiene el derecho a la vida..." en tanto otras señalan "Cada uno tendrá derecho a la vida..." Este asunto no es trivial, pues involucra precisamente la palabra persona. La traducción literal de "Jeder..." es todos o cada cual o cada uno, pero no persona. En inglés, el artículo $2 \mathrm{~N}^{\circ} 2$ de la Constitución alemana se traduce como "Everyone has the right to life...". Dice everyone (todos) no every person (toda persona). En la Constitución Alemana la palabra person se utiliza, de hecho, en el mismo artículo 2 $\mathrm{N}^{\circ}$ 2, cuando dice Die Freibeit der Person ist unverletzlich (la libertad de la persona es inviolable). Por tanto, cuando la Constitución germana emplea la palabra persona, no lo hace cuando asegura el derecho a la vida. Este sistema es distinto del chileno, que aplica la palabra persona a todos los titulares de derechos.

Así las cosas, ¿cómo ha interpretado la Corte Constitucional Alemana el artículo 2 $\mathrm{N}^{\circ}$ 2, que alude a todos o cada uno? La Corte ha tenido oportunidad de abordar el tema de la titularidad del derecho a la vida en el caso sobre aborto 39 BverGe I, de $1975 .{ }^{48}$ En ese fallo, la Corte declaró:

“b) Bei der Auslegung des Art. 2 Abs. 2 Satz 1 GG ist auszugehen von seinem Wortlaut: "Jeder hat das Recht auf Leben ...”. Leben im Sinne der geschichtlichen Existenz eines menschlichen Individuums besteht nach gesicherter biologisch-physiologischer Erkenntnis jedenfalls vom 14. Tage nach der Empfängnis (Nidation, Individuation) an $\left({ }^{49}\right)$. Der damit begonnene Entwicklungsprozeß ist ein kontinuierlicher Vorgang, der keine scharfen Einschnitte aufweist und eine genaue Abgrenzung der verschiedenen Entwicklungsstufen des menschlichen Lebens nicht zuläßt. Er ist auch nicht mit der Geburt beendet; die für die menschliche Persönlichkeit spezifischen Bewußtseinsphänomene z.B. treten erst längere Zeit nach der Geburt auf. Deshalb kann der Schutz des Art. 2 Abs. 2 Satz 1 GG weder auf den "fertigen” Menschen nach der Geburt noch auf den selbständig lebensfähigen nasciturus beschränkt werden. Das Recht auf Leben wird jedem gewährleistet, der "lebt"; zwischen einzelnen Abschnitten des sich entwickelnden Lebens vor der Geburt oder zwischen ungeborenem und geborenem Leben kann hier kein Unterschied gemacht werden. "Jeder" im Sinne des Art. 2 Abs. 2 Satz 1 GG ist "jeder Lebende", anders ausgedrückt: jedes Leben besitzende menschliche Individuum; “jeder" ist daher auch das noch ungeborene menschliche Wesen."

${ }^{48}$ En este caso, la Corte conoce de una impugnación, presentada por 193 miembros del Bundestag y 5 gobiernos estatales, de un proyecto de ley que modifica el Código Penal, autorizando el aborto sin requerir razones para ejecutarlo. La Corte acoge la petición, declarado que una liberalización del aborto sin causales no se justifica y señala en qué casos el legislador sí puede permitir el aborto.

${ }^{49}$ Referencia en el original, eliminada. 
En este considerando, la Corte declaró que se debe partir del lenguaje utilizado por el precepto. Agrega que la vida de un individuo humano existe desde el $14^{\circ}$ día de la concepción y que el proceso de desarrollo que allí comienza es un proceso continuo que no admite divisiones precisas que permitan dividir las etapas de desarrollo de la vida humana. Señala luego que ese proceso no termina ni siquiera con el nacimiento. Precisa la Corte que la protección del artículo $2 \mathrm{~N}^{\circ} 2$ no se puede limitar al ser humano "completado" 50 después del nacimiento o al niño que esté a punto de nacer y sea viable. Luego señala que el derecho a la vida se garantiza a todo aquel que viva, que ninguna distinción se puede hacer entre distintas etapas del desarrollo de la vida antes de nacer o entre nacidos y no nacidos y que todos o cada uno en el artículo $2 \mathrm{~N}^{\circ} 2$ son todos quienes viven, toda vida que posea individualidad humana; finalmente - dice la Corte- se trata del ser humano no nacido.

Así pues, la palabra persona no es central porque no aparece en el lenguaje de la Constitución, cuando alude al derecho a la vida. Por ende, la titularidad del derecho a la vida no se concede a la persona sino a todo ser humano vivo, desde antes de nacer. Esto es muy relevante, pues es el único caso de la jurisprudencia constitucional comparada en que se reconoce titularidad del derecho a la vida a quien no ha nacido. Sin embargo, ser titular del derecho a la vida desde antes de nacer no implica, constitucionalmente, prohibir el aborto de manera categórica. Al contrario, la Corte Constitucional alemana admitió diversas situaciones en las cuales existen poderosas razones que permiten terminar el embarazo. ${ }^{51,52}$

50 (comillas en el original).

${ }^{51}$ Por lo pronto, el legislador puede regular esta materia, dice la Corte, sección C.III.3 primer párrafo, del fallo. En cuanto a hipótesis en las cuales el legislador puede permitir el aborto, se trata de situaciones de inexigibilidad de continuar el embarazo para la mujer (así las llama la Corte). Las situaciones pueden corresponder a razones eugenésicas (malformaciones), éticas (criminológicas, como embarazo por violación), sociales (pobreza), entre otras. Dice el tribunal: "Unzumutbar erscheint die Fortsetzung der Schwangerschaft insbesondere, wenn sich erweist, daß der Abbruch erforderlich ist, um von der Schwangeren "eine Gefahr für ihr Leben oder die Gefahr einer schwerwiegenden Beeinträchtigung ihres Gesundheitszustandes abzuwenden" ( $§ 218$ b Nr. 1 StGB in der Fassung des Fünften Strafrechtsreformgesetzes). In diesem Fall steht ihr eigenes "Recht auf Leben und körperliche Unversehrtheit" (Art. 2 Abs. 2 Satz 1 GG) auf dem Spiel, dessen Aufopferung für das ungeborene Leben von ihr nicht erwartet werden kann. Darüber hinaus steht es dem Gesetzgeber frei, auch bei anderen außergewöhnlichen Belastungen für die Schwangere, die unter dem Gesichtspunkt der Unzumutbarkeit ähnlich schwer wie die in $§ 218 \mathrm{~b} \mathrm{Nr}$. 1 angeführten wiegen, den Schwangerschaftsabbruch straffrei zu lassen. Hierzu können insbesondere die in dem in der 6. Wahlperiode des Bundestages vorgelegten Entwurf der Bundesregierung enthaltenen und sowohl in der öffentlichen Diskussion wie auch im Verlauf des Gesetzgebungsverfahrens erörterten Fälle der eugenischen (vgl. § 218b Nr. 2 StGB), der ethischen (kriminologischen) und der sozialen oder Notlageindikation zum Schwangerschaftsabbruch gezählt werden. Bei den Beratungen des Sonderausschusses für die Strafrechtsreform (7. Wp., 25. Sitzung, StenBer. S. $1470 \mathrm{ff}$.) hat der Vertreter der Bundesregierung ausführlich und mit überzeugenden Gründen dargelegt, warum in diesen vier Indikationsfällen die Austragung der Schwangerschaft nicht als zumutbar erscheint. Der entscheidende Gesichtspunkt ist, daß in allen diesen Fällen ein anderes, vom Standpunkt der Verfassung aus ebenfalls schutzwürdiges Interesse sich mit solcher Dringlichkeit geltend macht, daß die staatliche Rechtsordnung nicht verlangen kann, die Schwangere müsse hier dem Recht des Ungeborenen unter allen Umständen den Vorrang einräumen.” Sección C.III.3. 3er párrafo.

52 En un gesto insólito, José Luis Cea cita este fallo (y el que se indica en la nota siguiente) en su libro para defender la postura contraria al aborto (ver Cea, ob. cit., pp. 105-108) dando a entender que el 
Ha habido otro caso en la jurisprudencia alemana, llamado aborto II, en el cual la Corte profundizó en las causales de inexigibilidad del embarazo, es decir, casos en que la mujer no puede tener la carga de soportarlo. De todos modos, mantuvo la doctrina sentada en el caso antes relatado, doctrina que se mantiene hasta la actualidad. ${ }^{53}$

\subsection{Tribunal Constitucional Español}

El derecho a la vida en la Constitución española se encuentra reconocido en el artículo 15. Allí establece: "Todos tienen derecho a la vida..." Como se puede apreciar, emplea el pronombre todos, en vez de recurrir a personas, algo parecido a lo que, hemos visto, sucede en la Ley Fundamental de Bonn. Sin embargo, en otros preceptos la situación es distinta. El artículo 16 garantiza la libertad ideológica, religiosa y de culto de los individuos; en el artículo 17 se asegura la libertad personal y la seguridad a todas las personas; y en el artículo 14 declara que los españoles son iguales ante la ley, entre otros. En consecuencia, para asignar titularidad de derechos la Constitución emplea las expresiones todos, personas, individuos y españoles. ${ }^{54}$ Pues bien, ¿es relevante constitucionalmente este asunto? Es necesario detenerse en la sentencia del Tribunal Constitucional, 53/1985, de 11/4/1985 sobre aborto. ${ }^{55}$ Afirma el Tribunal en el Fundamento Jurídico $\mathrm{N}^{\circ} 5$ :

“5. El art. 15 de la Constitución establece que "todos tienen derecho a la vida". La vida es un concepto indeterminado sobre el que se han dado respuestas plurívocas no sólo en razón de las distintas perspectivas (genética, médica, teológica, etc.), sino

TC alemán lo declaró inconstitucional. Lo que hace Cea es citar aquellas partes del fallo donde el TC declara al nasciturus titular del derecho a la vida y ordena protegerlo, pero omite citar aquellas otras donde el TC alemán reconoce diversas causas que justifican constitucionalmente el aborto. Por tanto, cualquier persona que desconozca la jurisprudencia constitucional alemana creerá, a partir del texto de Cea, que el TC alemán declaró inconstitucional el aborto.

53 Caso 88 BVerfge203, de 1993. Dice la Corte: "Für die Pflicht zum Austragen des Kindes folgt daraus, daß neben der hergebrachten medizinischen Indikation auch die kriminologische und -ihre hinreichend genaue Umgrenzung vorausgesetzt- die embryopathische Indikation als Ausnahmetatbestände vor der Verfassung Bestand haben können; für andere Notlagen gilt dies nur dann, wenn in ihrer Umschreibung die Schwere des hier vorauszusetzenden sozialen oder psychisch-personalen Konflikts deutlich erkennbar wird, so daß - unter dem Gesichtspunkt der Unzumutbarkeit betrachtet - die Kongruenz mit den anderen Indikationsfällen gewahrt bleibt.” Extracto de la sección D.2. (c) (bb) del fallo. De este párrafo se colige que, además de las hipótesis de indicación médica, criminológica o embriopática que pueden justificar el aborto, podría haber otras situaciones en las cuales el aborto también se justifique, como un caso de grave conflicto psicológico o social de la mujer, que claramente constituya una carga no razonable.

${ }^{54}$ En este aspecto, la constitución española es distinta de la chilena, que emplea el mismo concepto para todos los titulares: persona.

55 En este caso, el TC conoce de la impugnación de un proyecto de ley que autoriza el aborto (inversa la situación al caso de EE.UU. y parecido al alemán). El TC acoge la impugnación, declarando inconstitucional el proyecto de ley, no en razón de los supuestos en que declara no punible el aborto, sino por incumplir en su regulación exigencias constitucionales derivadas del artículo 15 de la Constitución. En cuanto al aborto, el TC declara que la Constitución lo permite. Ver Fundamentos Jurídicos No 9, 10, 11 y 12. 
también en virtud de los diversos criterios mantenidos por los especialistas dentro de cada uno de los puntos de vista considerados, y en cuya evaluación y discusión no podemos ni tenemos que entrar aquí. Sin embargo, no es posible resolver constitucionalmente el presente recurso sin partir de una noción de la vida que sirva de base para determinar el alcance del mencionado precepto. Desde el punto de vista de la cuestión planteada basta con precisar: a) Que la vida humana es un devenir, un proceso que comienza con la gestación, en el curso de la cual una realidad biológica va tomando corpórea y sensitivamente configuración humana, y que termina en la muerte; es un continuo sometido por efectos del tiempo a cambios cualitativos de naturaleza somática y psíquica que tienen un reflejo en el estatus jurídico público y privado del sujeto vital. b) Que la gestación ha generado un tertium existencialmente distinto de la madre, aunque alojado en el seno de ésta. c) Que dentro de los cambios cualitativos en el desarrollo del proceso vital y partiendo del supuesto de que la vida es una realidad desde el inicio de la gestación, tiene particular relevancia el nacimiento, ya que significa el paso de la vida albergada en el seno materno a la vida albergada en la sociedad, bien que con distintas especificaciones y modalidades a lo largo del curso vital. Y previamente al nacimiento tiene especial trascendencia el momento a partir del cual el nasciturus es ya susceptible de vida independiente de la madre, esto es, de adquirir plena individualidad humana.

De las consideraciones anteriores se deduce que si la Constitución protege la vida con la relevancia a que antes se ha hecho mención, no puede desprotegerla en aquella etapa de su proceso que no sólo es condición para la vida independiente del claustro materno, sino que es también un momento del desarrollo de la vida misma; por lo que ha de concluirse que la vida del nasciturus, en cuanto éste encarna un valor fundamental -la vida humana- garantizado en el art. 15 de la Constitución, constituye un bien jurídico cuya protección encuentra en dicho precepto fundamento constitucional.

Esta conclusión resulta también de los debates parlamentarios en torno a la elaboración del mencionado artículo del texto constitucional, cuya cercanía en el tiempo justifica su utilización como elemento interpretativo. En el Pleno del Congreso fue defendida una enmienda -aprobada por mayoría- que proponía utilizar el término "todos" en sustitución de la expresión "todas las personas" -introducida en el seno de la Comisión para modificar la primitiva redacción del precepto en el Anteproyecto por estimar que era "técnicamente más correcta"- con la finalidad de incluir al nasciturus y de evitar, por otra parte, que con la palabra "persona" se entendiera incorporado el concepto de la misma elaborado en otras disciplinas jurídicas específicas, como la civil y la penal, que, de otra forma, podría entenderse asumido por la Constitución. La ambigüedad del término "todos" en la expresión "todos tienen derecho a la vida" no fue despejada, sin embargo, durante los debates por lo que se refiere a la extensión de la titularidad del derecho, pero en cualquier caso, como señaló el defensor de la enmienda, constituía una fórmula abierta que se estimaba suficiente para basar en ella la defensa del nasciturus. El precepto fue aprobado posteriormente en el Senado por 162 votos a favor, ninguno en contra y 
dos abstenciones. En definitiva, el sentido objetivo del debate parlamentario corrobora que el nasciturus está protegido por el art. 15 de la Constitución aun cuando no permite afirmar que sea titular del derecho fundamental."

La idea central de este considerando, que aparece en la última línea citada, es que el nasciturus no se encuentra comprendido por la expresión "todos" y, por ello, no es titular del derecho a la vida. El concepto de persona no es relevante aquí. Sin embargo, el nasciturus es un bien jurídico que la Constitución manda proteger pues encarna un valor fundamental: la vida humana. En este sentido, el fallo español encontrará un símil en la jurisprudencia colombiana. Finalmente, cabe decir que esta protección del nasciturus será determinada por el legislador, ${ }^{56}$ el que puede autorizar el aborto. ${ }^{57}$ La doctrina de este fallo se encuentra vigente.

\subsection{La Corte Constitucional Colombiana}

La Constitución de Colombia establece, en el artículo 11, "El derecho a la vida es inviolable...".

El capítulo I sobre Derechos Fundamentales comienza con este artículo 11, sin recurrir a un encabezado general que permita tener una idea del titular de los derechos. Sin embargo, en muchas oportunidades suele utilizar la voz persona como titular del derecho. Así por ejemplo, "Todas las personas nacen libres e iguales ante la ley..." (art. 13); "Toda persona tiene derecho al reconocimiento de su personalidad jurídica..." (art. 14); "Todas las personas tienen derecho a su intimidad personal y familiar y a su buen nombre... (art. 15); "Todas las personas tienen derecho al libre desarrollo de su personalidad...”. Sin embargo, en el caso del derecho a la vida, no lo hizo. ¿Cómo ha entendido este precepto la Corte Constitucional? La Corte colombiana se ha pronunciado sobre acciones constitucionales relativas al aborto en varias oportunidades. Aquí aludiremos a las dos más importantes, de 1994 y 2006:

a) Fallo de 1994. La primera vez que la Corte tuvo oportunidad de abordar este asunto fue en la sentencia C-133, de $1994 .{ }^{58}$ En ese caso, la Corte sostuvo:

${ }^{56}$ El fundamento Jurídico $\mathrm{N}^{\circ} 6$ lo aclara: “...esta protección que la Constitución dispensa al nasciturus implica para el Estado con carácter general dos obligaciones: La de abstenerse de interrumpir o de obstaculizar el proceso natural de gestación, y la de establecer un sistema legal para la defensa de la vida que suponga una protección efectiva de la misma y que, dado el carácter fundamental de la vida, incluya también, como última garantía, las normas penales. Ello no significa que dicha protección haya de revestir carácter absoluto; pues, como sucede en relación con todos los bienes y derechos constitucionalmente reconocidos, en determinados supuestos puede y aun debe estar sujeta a limitaciones, como veremos posteriormente."

57 La permisión constitucional del aborto aparece, entre otros, en los Fundamentos Jurídicos $\mathrm{N}^{\circ} 9$, 10,11 y 12 .

58 Este es un caso de acción pública de inconstitucionalidad, mediante la cual se demandó la inconstitucionalidad del artículo 343 del Código Penal. Se trata de la penalización del aborto. La Corte rechaza la solicitud, apoyando la norma penal. 
"Es cierto, que nuestra Constitución Política reconoce expresamente el derecho inviolable a la vida a quienes son personas pertenecientes al género humano; pero de allí no se sigue que la vida humana latente en el nasciturus, carezca de protección constitucional. En efecto, si el valor esencial protegido por el ordenamiento superior es la vida humana, necesariamente debe colegirse que en donde haya vida, debe existir el consecuente amparo estatal. En otros términos la Constitución no sólo protege el producto de la concepción que se plasma en el nacimiento, el cual determina la existencia de la persona jurídica natural, en los términos de las regulaciones legales, sino el proceso mismo de la vida humana, que se inicia con la concepción, se desarrolla y perfecciona luego con el feto, y adquiere individualidad con el nacimiento. La vida que la Constitución Política protege, comienza desde el instante de la gestación, dado que la protección de la vida en la etapa de su proceso en el cuerpo materno, es condición necesaria para la vida independiente del ser humano fuera del vientre de la madre. Por otra parte, la concepción, genera un tercer ser que existencialmente es diferente de la madre, y cuyo desarrollo y perfeccionamiento para adquirir viabilidad de vida independiente, concretada con el nacimiento, no puede quedar al arbitrio de la libre decisión de la embarazada. En virtud de lo anterior, el Estado tiene la obligación de establecer, para la defensa de la vida que se inicia con la concepción, un sistema de protección legal efectivo..."59

Como se puede apreciar, el nasciturus no se considera persona, pero goza de protección constitucional, pues el valor esencial protegido es la vida humana. Por ende, la protección debe dispensarse desde la concepción. Agrega un poco más adelante la Corte: "La vida del nasciturus encarna un valor fundamental, por la esperanza de su existencia como persona que representa, y por su estado de indefensión manifiesto que requiere de la especial protección del Estado." ${ }^{60}$ Esta doctrina llevó a la Corte a estimar que el aborto debía penalizarse ${ }^{61}$ y por ello rechazó la petición del demandante de declarar inconstitucional la norma penal.

b) Fallo de 2006. Doce años después del primer fallo, la postura de la Corte cambió, con el fallo C-355/06, también sobre aborto. ${ }^{62}$ Una de las razones fundamentales del cambio -en lo que atinge a la titularidad y situación del nasciturus - es la distinción entre vida y derecho a la vida, como veremos. En este fallo dispuso:

59 Sección VII, 4, párrafos 6-9.

60 Sección VII, 4, párrafo 11.

61 “...el Estado tiene la obligación de establecer, para la defensa de la vida que se inicia con la concepción, un sistema de protección legal efectivo, y dado el carácter fundamental del derecho a la vida, su instrumentación necesariamente debe incluir la adopción de normas penales..." Sección VII, 4, párrafo 9.

62 En este caso, al igual que en el anterior, se trató de acción pública de inconstitucionalidad, mediante la cual se demandó la inconstitucionalidad (ahora) de varios preceptos Código Penal, el cual había sido modificado con posterioridad al caso C-133. En esta oportunidad, la Corte acogió la acción y declaró inconstitucionales algunas de las disposiciones del Código Penal. Sentencia C-355/06. Bogotá, D. C., diez (10) de mayo de dos mil seis (2006). 
"Ahora bien. Dentro del ordenamiento constitucional la vida tiene diferentes tratamientos normativos, pudiendo distinguirse el derecho a la vida consagrado en el artículo 11 constitucional, de la vida como bien jurídico protegido por la Constitución. El derecho a la vida supone la titularidad para su ejercicio y dicha titularidad, como la de todos los derechos está restringida a la persona humana, mientras que la protección de la vida se predica incluso respecto de quienes no han alcanzado esta condición." 63 (...) "En relación con esta distinción cabe recordar, que por ejemplo en la sentencia C-133 de 1994, la Corte no reconoció expresamente al nasciturus el carácter de persona humana y titular del derecho a la vida..."64 (...) “...considera esta Corporación que determinar el momento exacto a partir del cual se inicia la vida humana es un problema al cual se han dado varias respuestas, no sólo desde distintas perspectivas como la genética, la médica, la religiosa o la moral, entre otras, sino también en virtud de los diversos criterios expuestos por cada uno de los respectivos especialistas, y cuya evaluación no le corresponde a la Corte Constitucional en esta decisión." ${ }^{65}$ (...) “...más allá de la discusión de si el nasciturus es una persona y en esa calidad titular de derechos fundamentales, es una vida humana en gestación, y como tal el Estado colombiano tiene un claro deber de protección..."66 (...) “...dentro de los límites fijados en la Constitución, determinar en cada caso específico la extensión, el tipo y la modalidad de la protección a la vida del que está por nacer corresponde al legislador, quien debe establecer las medidas apropiadas para garantizar que dicha protección sea efectiva..."67 (...) "Conforme a lo expuesto, la vida y el derecho a la vida son fenómenos diferentes. La vida humana transcurre en distintas etapas y se manifiesta de diferentes formas, las que a su vez tienen una protección jurídica distinta. El ordenamiento jurídico, si bien es verdad, que otorga protección al nasciturus, no la otorga en el mismo grado e intensidad que a la persona humana..."68

Estos párrafos permiten advertir que la Corte distingue con claridad vida de derecho a la vida, y reconoce que el nasciturus no es titular del derecho a la vida porque no es persona, aunque su vida debe ser protegida por mandato de la Constitución, pues toda vida es un bien digno de protección. De todos modos, la forma de brindar protección a la vida queda entregada al legislador, quien debe proceder dentro de los límites fijados

63 Sección 5, párrafo 12.

64 Sección 5, párrafo 13. Sin embargo, como se vio anteriormente, ese fallo de 1994 rechazó una solicitud de declaración de inconstitucionalidad de la prohibición del aborto.

65 Sección 5, párrafo 16.

66 Sección 5, párrafo 17.

67 Sección 5, párrafo 18.

68 Sección 5, párrafo 20. 
por la Carta Fundamental, y sin vulnerar los derechos de la mujer. ${ }^{69}$ En esa virtud, el legislador puede permitir el aborto en ciertos casos. ${ }^{70}$

\section{Jurisprudencia internacional}

En esta sección veremos dos casos de definición de persona y titularidad del derecho a la vida en la jurisprudencia internacional: la Comisión Interamericana de Derechos Humanos y la Corte Europea de Derechos Humanos.

\subsection{Comisión Interamericana de Derechos Humanos. Caso Baby Boy. ${ }^{71}$}

En ese caso, se invoca el artículo I de la Declaración Americana de Derechos y Deberes del Hombre "Todo ser humano tiene derecho a la vida...", para solicitar se declare que el aborto es contrario a la Declaración. Señala el recurrente que ese precepto debe interpretarse considerando:

“a) Los trabajos preparatorios, la discusión del Proyecto de la Declaración durante la IX Conferencia Internacional de Estados Americanos en Bogotá en 1948, y el voto final demuestra que la intención de la conferencia fue la de proteger el derecho a la vida "desde el momento de la concepción” y "b) La Convención Interamericana sobre Derechos Humanos, promulgada para impulsar los altos fines de la Declaración y como un corolario de ella, da una definición del derecho a la vida en el artículo 4.1: "Este derecho estará protegido por la ley y, en general, a partir del momento de la concepción”.

69 "De manera que estas consideraciones habrán de ser tenidas en cuenta por el legislador, si considera conveniente fijar políticas públicas en materia de aborto, incluidas la penal en aquellos aspectos en que la Constitución lo permita, respetando los derechos de las mujeres." Sección 5 párrafo 21.

${ }^{70}$ En la sección 10 del fallo, la Corte declara en qué casos el aborto no puede prohibirse (no puede constituir delito): cuando se trata de un embarazo que es resultado de una conducta constitutiva de acceso carnal, o acto sexual sin consentimiento, abusivo o de inseminación artificial o transferencia de óvulo fecundado no consentidas (sección 10.1 párrafo 14 en relación con párrafo 16), o incesto (párrafo 19); o cuando la vida o la salud de la mujer están amenazadas (párrafo 23. La salud puede ser física o mental, párrafo 27); o malformaciones genéticas del feto que por su gravedad lo tornen inviable (párrafo 29). Finaliza la Corte diciendo: “...la prohibición completa e incondicional del aborto en todas las circunstancias es abiertamente desproporcionada porque anula completamente derechos de la mujer embarazada garantizados por la Constitución de 1991 y por tratados internacionales de derechos humanos que hacen parte del bloque de constitucionalidad." Sección 10.2 párrafo 38.

71 RESOLUCIÓN Nº 23/81. CASO 2141. ESTADOS UNIDOS DE AMÉRICA. 6 de marzo de 1981. Este es un caso en que se cometió un aborto y se demanda a EE.UU. por no sancionar al responsable; además, se lo responsabiliza por su jurisprudencia que permite el aborto. A la fecha de los hechos, la Convención Americana no había entrado en vigor, de modo que sólo puede aplicarse el procedimiento de los artículos 53 al 57 del Reglamento de la Comisión. La Comisión desecha el caso. 
La Comisión desestima la petición. En relación con el argumento de la letra a) considera que:

“19. La breve historia legislativa de la Declaración no apoya el argumento de los peticionarios, como puede inferirse de las siguientes informaciones y documentos:..."

"b) El artículo 1, sobre el derecho a la vida, del Proyecto sometido por el Comité Jurídico expresa: "Toda persona tiene derecho a la vida. Este derecho se extiende al derecho a la vida desde el momento de la concepción; al derecho a la vida de los incurables, imbéciles y dementes. La pena capital puede aplicarse únicamente en casos en que se haya prescrito por leyes preexistentes por delitos de extrema gravedad”. “c) Se formó un grupo de trabajo para que estudiara las observaciones y enmiendas introducidas por los delegados y preparara un documento aceptable. El grupo sometió, en efecto, a la sexta comisión, un nuevo texto preliminar con el título de Declaración Americana de los Derechos y Deberes Fundamentales del Hombre, cuyo artículo I decía: "Todo ser humano tiene derecho a la vida, libertad, seguridad, o integridad de su persona”. "e) En relación con el derecho a la vida, la definición dada en el Proyecto del Comité Jurídico era incompatible con las leyes que rigen la pena capital y aborto en la mayoría de los Estados americanos. En efecto, la aceptación de este concepto absoluto -el derecho a la vida desde el momento de la concepción- habría implicado la derogación de los artículos de los códigos penales que regían en 1948 en muchos países, porque dichos artículos excluían la sanción penal por el crimen de aborto si se lo ejecutaba en uno o más de los siguientes casos..." "g) El 22 de abril de 1948, el nuevo artículo I de la Declaración, preparado por el grupo de trabajo, fue aprobado por la comisión sexta con un pequeño cambio de redacción en el texto español..." "h) En consecuencia, Estados Unidos tiene razón en recusar la suposición de los peticionarios de que el artículo I de la Declaración ha incorporado la noción de que el derecho a la vida existe desde el momento de la concepción. En realidad, la conferencia enfrentó esta cuestión y decidió no adoptar una redacción que hubiera claramente establecido ese principio."

En relación, ahora, con lo señalado en la letra b), la Corte también desestima la petición considerando que:

"25. Para conciliar los puntos de vista que insistían sobre el concepto de "desde el momento de la concepción”, con las objeciones suscitadas, desde la Conferencia de Bogotá sobre la base de la legislación de los Estados americanos que permitían el aborto, inter-alia, para salvar la vida de la madre y en caso de estupro, la CIDH, volvió a redactar el artículo 2 (derecho a la vida) y decidió por mayoría de votos introducir, antes de ese concepto, las palabras "en general." Ese arreglo fue el origen del nuevo texto del artículo 2 "1. Toda persona tiene el derecho a que se respete su vida. Este derecho estará protegido por la ley, en general, desde el momento de la concepción..." "26. El relator propuso, en esta segunda oportunidad de discusión de la definición del derecho a la vida, eliminar la frase final entera “...en general, desde el momento de la concepción”. Repitió el razonamiento de su opinión disidente, es decir, que se 
basaba en las leyes sobre aborto vigentes en la mayoría de los Estados americanos, con la siguiente adición: "para evitar cualquier posibilidad de conflicto con el artículo 6, párrafo 1, del Pacto de las Naciones Unidas sobre Derecho Cívicos y Políticos, que establece este derecho únicamente de manera general..." "27. Sin embargo, la mayoría de miembros de la Comisión creyeron que, por razones de principio, era fundamental formular la disposición sobre la protección del derecho a la vida en la forma recomendada al Consejo de la OEA en su Opinión (primera parte). Se decidió, por tanto, mantener el texto del párrafo 1, sin cambios." "28. En la conferencia diplomática que aprobó la Convención Americana, las delegaciones del Brasil y de la República Dominicana presentaron enmiendas separadas de eliminación de la frase final del párrafo 1 del artículo 3 (derecho a la vida), o sea: "en general, desde el momento de la concepción”... “29. La delegación del Ecuador apoyó, en cambio, la eliminación de las palabras "en general." Por fin, por voto de la mayoría, la conferencia adoptó el texto preliminar sometido por la CIDH y aprobado por el Consejo de la OEA el cual continúa hasta el presente como texto del artículo 4, párrafo 1, de la Convención Americana...” “30. A la luz de los antecedentes expuestos, queda en claro que la interpretación que adjudican los peticionarios de la definición del derecho a la vida formulada por la Convención Americana es incorrecta. La adición de la frase "en general, desde el momento de la concepción” no significa que quienes formularon la Convención tuviesen la intención de modificar el concepto de derecho a la vida que prevaleció en Bogotá, cuando aprobaron la Declaración Americana. Las implicaciones jurídicas de la cláusula "en general, desde el momento de la concepción" son substancialmente diferentes de las de la cláusula más corta “desde el momento de la concepción”...”.

Como se puede advertir, la comisión resuelve este caso sin efectuar un análisis de la palabra persona. Más bien se limita responder la petición (declarar que se tiene derecho a la vida desde la concepción), rechazando la solicitud y señalando que a partir de la Declaración Americana y de la Convención Americana, un derecho a la vida no se tiene desde la concepción debido a la cláusula "y en general”.

\subsection{La Corte Europea de DDHH. Caso Vo. contra Francia ${ }^{72}$}

En este caso está en discusión la interpretación del artículo 2 de la Convención para la Protección de los Derechos Humanos y Libertades Fundamentales, que dispone: "1. Everyone's right to life shall be protected by law. No one shall be deprived of his life intentionally save in the execution of a sentence of a court following his conviction of a crime for which this penalty is provided by law." Acerca del titular del derecho, la Corte considera que:

72 Application no. 53924/00, Judgment, Strasbourg, 8 de Julio, 2004. En este caso, una mujer perdió su hijo en gestación por negligencia médica. Conforme la ley francesa, eso no constituye homicidio no intencional. Por eso, la mujer demanda al Estado de Francia por violar el artículo 2 de la Convención. La Corte desecha el caso, estimando que no se produce tal violación. 
$\mathrm{C}^{\circ} 82$ párrafo $2^{\circ}$ : "It follows that the issue of when the right to life begins comes within the margin of appreciation which the Court generally considers that States should enjoy in this sphere (sic) The reasons for that conclusion are, firstly, that the issue of such protection has not been resolved within the majority of the Contracting States themselves, in France in particular, where it is the subject of debate (sic) and, secondly, that there is no European consensus on the scientific and legal definition of the beginning of life (sic)." $\mathrm{C}^{\mathrm{o}} 83$...."It is clear from this overview that in France, the nature and legal status of the embryo and/or the foetus are currently not defined and that the manner in which it is to be protected will be determined by very varied forces within French society." C ${ }^{\circ} 84$. "At European level, the Court observes that there is no consensus on the nature and status of the embryo and/or foetus (...) At best, it may be regarded as common ground between States that the embryo/foetus belongs to the human race. The potentiality of that being and its capacity to become a person (...) require protection in the name of human dignity, without making it a "person" with the "right to life" for the purposes of Article 2. The Oviedo Convention on Human Rights and Biomedicine, indeed, is careful not to give a definition of the term "everyone" and its explanatory report indicates that, in the absence of a unanimous agreement on the definition, the member States decided to allow domestic law to provide clarifications for the purposes of the application of that Convention (...) The same is true of the Additional Protocol on the Prohibition of Cloning Human Beings and the draft Additional Protocol on Biomedical Research, which do not define the concept of "human being" (...) C 85 . "Having regard to the foregoing, the Court is convinced that it is neither desirable, nor even possible as matters stand, to answer in the abstract the question whether the unborn child is a person for the purposes of Article 2 of the Convention..." $\mathrm{C}^{\circ}$ 86. "In that connection, it observes that the unborn child's lack of a clear legal status does not necessarily deprive it of all protection under French law...."

Se puede apreciar que la Corte europea se negó a considerar que el artículo 2 de la Convención confiera al feto derecho a la vida o carácter de persona, básicamente en atención a que el asunto no se encuentra zanjado en la unión europea, lo que no significa que deba estar desprovisto de protección.

\section{Comentarios Sobre la TITUlaridad DEL DERECHO A LA VIDA} Y EL CONCEPTO DE PERSONA

\section{Comentarios sobre la doctrina nacional}

Hemos visto que la postura mayoritaria se desglosa en varios puntos. Los revisaremos a continuación. 
1.1. Se afirma que el ser humano es persona desde el momento de la concepción o fecundación.

Esta es quizá la idea central de la postura mayoritaria, pues a partir de ella se desprende el estatuto jurídico y moral que se asocia al nasciturus. Esta postura se puede explicar por la orientación religiosa que suscriben los diversos autores, ${ }^{73}$ según la cual el ser humano recién concebido debe ser valorado de igual manera que el ser humano ya ha nacido. ${ }^{74}$ Dicho de otro modo: desde que existe un ser humano, su valoración moral debe ser la misma cualquier que sea su etapa de desarrollo. Existen varias razones para cuestionar esta posición:

a) En primer lugar, toda fundamentación religiosa suscita dificultades obvias vinculadas a un estado de derecho laico, democrático, tolerante e inclusivo. En segundo lugar, esa postura religiosa parece contradictoria. Se supone que asigna el mismo valor a la vida prenatal y a la nacida, pero en verdad no es así: la vida prenatal no se puede eliminar nunca en tanto la vida nacida sí. El caso más obvio es la pena de muerte, que sigue siendo aceptada por el Catecismo de la Iglesia Católica. ${ }^{75}$

73 Prácticamente toda la doctrina dominante citada en la sección II, con exclusión de Verdugo y Pfeffer. El ejemplo más reciente en Chile parece ser en el texto de Ugarte, J.J., El Derecho de la vida, ob. cit. Otro ejemplo es Cea: en el capítulo relativo al derecho a la vida cita a Juan Pablo II, ob. cit., p. 86. En la misma línea van Corral, Soto Kloss.

Cecilia Medina apunta que cuando en un país del continente americano se penaliza todo aborto (y son los casos de Chile y el Salvador), aquello tiene como un importante factor explicativo el hecho de que la Iglesia Católica tenga mucho poder. Ver Medina, C., La Convención Americana: Teoría y Jurisprudencia. Centro de Derechos Humanos, Facultad de Derecho, Universidad de Chile, Santiago, 2003, pp. 67-68.

${ }^{74}$ Muchos de los autores que conforman la postura mayoritaria recurren a referencias religiosas. Por ejemplo, Cea y Ugarte, en la nota anterior; Carrasco, cuando alude a la tradición cristiano-occidental, en p. 54 y cita la doctrina oficial de la Iglesia Católica, p. 41, ob. cit.; Zapata, quien cita la Iglesia Católica, p. 375 ob. cit.; Corral también alude a la Iglesia Católica, p. 442 en "Admisibilidad jurídica de las técnicas de procreación artificial.” ob. cit.; Precht alude a la moral católica, p. 509 y 511-512, y cita una encíclica, p. 515, ob. cit.; Varela cita fuentes católicas, en nota a pie de página $\mathrm{N}^{\circ}$ 9, p. 204, ob. cit., otros autores como Silva, ob. cit.; Corral, en "El concepto jurídico de persona. Una propuesta de reconstrucción unitaria." ob. cit.; y Ugarte en sus dos obras, citan fuentes iusnaturalistas católicas, como Tomás de Aquino; Evans señala que la vida es un don de Dios, p. 113, ob. cit., y Soto Kloss en sus tres obras citadas alude a Juan Pablo II, p. 59 y efectúa diferentes referencias a Dios en las pp. 58-59 en "Derecho a la vida y recurso de protección”, Revista de Derecho y Jurisprudencia y Gaceta de los Tribunales, Tomo LXXXI, No 2, mayo-agosto, Santiago, 1984, Primera Parte; alude al Creador en la p. 59 en "El derecho a la vida y la noción de persona en la Constitución." Revista de Derecho y Jurisprudencia y Gaceta de los Tribunales. Tomo LXXXVIII, N ${ }^{\circ} 3$, 1991, Primera parte; y alude a Cristo y la Iglesia en las pp. 138-139, 142 en "La noción de persona en la Constitución", Revista de Derecho Público, Nos. 50, julio-diciembre, Santiago, 1991; Vivanco es otro ejemplo: alude a la "doctrina moral católica, p. 264; señala que la estructura de la Constitución descansa una concepción humanista y "cristiana”..., p. 245; cita a autores pontificios, como Davanzo, p. 264, Cuervo, p. 265 , etc. Demás está decir que es tradicional en una perspectiva más amplia, citar a Spaemann, como hace reiteradamente Corral y también Vivanco.

75 "La preservación del bien común de la sociedad exige colocar al agresor en estado de no poder causar perjuicio. Por este motivo la enseñanza tradicional de la Iglesia ha reconocido el justo fundamento del derecho y deber de la legítima autoridad pública para aplicar penas proporcionadas a la gravedad del delito, sin excluir, en casos de extrema gravedad, el recurso a la pena de muerte. Por motivos análogos quie- 
b) En segundo lugar, esa postura no concuerda con la valoración que subyace en el propio ordenamiento jurídico chileno. En efecto, distintas normas revelan claramente que la valoración del nasciturus es distinta de la del nacido. Eso explica que el Código Civil exija el nacimiento para conferir existencia legal; que la Constitución dé un tratamiento distinto al que está por nacer (en el artículo $19 \mathrm{~N}^{\circ} 1$ inciso $2^{\circ}$ ); que el Código Penal establezca para el aborto una pena inferior al infanticidio y al parricidio (y regule el aborto en una sección distinta de los delitos contra las personas), etc. Sobre este punto, Gómez argumenta que si no existiera una diferencia de valoración y si, por ende, el fallo de la Suprema (sobre la píldora, de 2001) estuviere en lo correcto “...la diferencia de trato que la ley da al homicidio y al aborto sería inconstitucional por establecer una diferencia constitucionalmente prohibida."76

Se dijo que el $19 \mathrm{~N}^{\circ} 1$ la Constitución separa el reconocimiento del derecho a la vida de todas las personas de la protección que ordena brindar al que está por nacer. La doctrina mayoritaria no se hace cargo de este punto central. Que la Constitución contenga dos disposiciones revela, sin lugar a dudas, un tratamiento diverso para el nasciturus. Gómez proporciona la explicación:

"[E]sta diferencia de enunciados, entre el inciso primero y el segundo, expresa una valoración completamente distinta de parte del Constituyente..."77 "Si el no nacido pero concebido era una persona desde el momento de la concepción, entonces qué sentido tiene destinarle un inciso especial diferente del tratamiento general del derecho a la vida." "[S]i el feto goza del derecho a la vida, constitucionalmente protegido, entonces encargarle al legislador su protección resulta superfluo, pues ya se encuentra protegido por el inciso primero del artículo $19 \mathrm{~N}^{\circ} 1$ que asegura a todas las personas el derecho a la vida.,"78

Sobre este punto, Bascuñán explica la tesis de la exigibilidad diferenciada:

"El fundamento de la tesis de la diferenciación entre la protección constitucional de la vida del nasciturus y la protección del derecho a la vida de las personas no es de carácter histórico, sino sistemático y valorativo. Lo relevante como premisa no es el hecho histórico del voto de mayoría, sino el reconocimiento expresado en ese voto de un principio constitucional, cual es, el de la exigibilidad diferenciada del deber de abstenerse de matar al nasciturus en relación con la exigibilidad del deber de abstenerse de matar a otro. ${ }^{79}$

nes poseen la autoridad tienen el derecho de rechazar por medio de las armas a los agresores de la sociedad que tienen a su cargo." Catecismo de la Iglesia Católica. Ediciones Trípode. Segunda edición. Caracas, 1993. Sección 2266, 1er párrafo.

76 Gómez, ob cit., p. 311.

77 Gómez, ob. cit., p. 310.

78 Gómez, ob. cit., pp. 310-311.

79 Bascuñán, ob. cit., pp. 66-67. 
Luego agrega:

[S]i la prohibición de matar a un ser humano nacido encuentra sus excepciones en la legítima defensa y en el estado de necesidad defensivo, pero no en el estado de necesidad agresivo, ¿qué excepciones cabe adicionalmente reconocer respecto de la prohibición de matar al nasciturus? De lo dicho se desprende que hay dos posibles sentidos en los cuales la prohibición de atentar contra la vida del nasciturus puede verse relativizada en comparación con la prohibición de atentar contra la vida de los nacidos: (a) la aceptación del estado de necesidad agresivo, y (b) la atenuación de las exigencias del estándar de ponderación de intereses en el estado de necesidad defensivo. ${ }^{80}$

Que la Constitución efectúe este diverso tratamiento no es extraño. De hecho, y como hemos visto, en la jurisprudencia constitucional comparada e internacional jamás un tribunal ha declarado que el nasciturus sea persona. ${ }^{81} \mathrm{El}$ único sentido coherente de ese enunciado es que establece un deber de protección para la vida del no nacido. Si se lo entendiera como confiriendo un derecho a la vida para el no nacido, esa norma sería redundante con el inciso $1^{\circ} .{ }^{82}$ Además, habría tenido más sentido prohibir directamente el aborto si esa hubiere sido la intención del legislador, pero no nos adentraremos en ese asunto. ${ }^{83}$

c) Por otra parte, desde el punto de vista de las normas jurídicas vigentes, el Código Civil claramente estipula que la existencia legal de la persona principia con el nacimiento. La doctrina mayoritaria no ha proporcionado razones atendibles de por qué habríamos de hacer caso omiso de esas reglas. Una autora ${ }^{84}$ titula una sección de su libro "Inconveniencia de aplicar al no nacido el concepto de persona del Código Civil chileno", pero en ella no proporciona razones constitucionales para apartarse de la definición legal, salvo claro la inconveniencia que esa definición legal implica para su postura personal sobre el tema.

d) No hay en la Constitución ningún indicio de que la palabra persona se aplique al nasciturus. Si seguimos la metodología utilizada por la Corte de los EE.UU. en el caso Roe vs. Wade, constataremos que la palabra persona aparece en 63 oportunidades en diversas partes de la Constitución chilena, pero en ninguna de ellas se utiliza alguna

${ }^{80}$ Bascuñán, ob. cit., p. 71.

81 Ya explicamos que en el caso alemán se reconoció que el nasciturus es titular del derecho a la vida, pero no persona, y vimos por qué. Sin embargo, esto no abona la postura mayoritaria en Chile porque aunque en Alemania se le reconozca titularidad del derecho a la vida, de todos modos su derecho a la vida no es absoluto y el aborto está constitucionalmente permitido.

82 Ver Gómez y Bascuñán, ob. cit.

${ }^{83}$ Quien crea pertinente ver las actas, puede consultar los resúmenes y ordenación que presenta Gustavo Fiamma, en Fiamma, G., "El Derecho a la vida. Antecedentes en las Actas de la Comisión de Estudios Constitucionales”. En Revista de Derecho Público, No 27 (enero-junio), 1980.

${ }^{84}$ Vivanco, ob. cit., pp. 254 y ss. 
fórmula lingüística que sugiera que ese concepto se aplica, además de los nacidos, a los no nacidos. ${ }^{85}$

e) Algunos representantes de la postura mayoritaria proporcionan extensas explicaciones de embriología para sostener que el recién concebido es una persona. ${ }^{86}$ Por lo pronto, esta estrategia es discutible, pues el asunto es constitucional, no biológico. No son los biólogos los que han de resolver temas constitucionales. Un ejemplo: no cabe duda que los nacidos son personas desde el punto de vista biológico, pero eso no significa que no se pueda terminar con sus vidas de manera justificada. ${ }^{87}$ Esto revela que la biología no tiene nada que hacer en este tema. En segundo lugar, los textos de embriología no suelen utilizar la palabra persona. Cuando se describen las diversas etapas del desarrollo desde el día 1 de la concepción, los textos de embriología no suelen apurarse -como hacen algunos comentaristas chilenos- en etiquetar a ese ser en desarrollo como una persona. ${ }^{88}$ Por otra parte, cuando la postura mayoritaria afirma que existe una persona desde el momento de la fecundación lo que supone es que desde ese momento existe un individuo pues, si no hay un individuo, no puede haber una persona. Pues bien, antes del día 14 contado desde la concepción no es posible hablar de un individuo. El ovocito fecundado puede tener diversos destinos: puede transformarse en una mola y no desarrollarse como individuo, puede dar lugar a varios individuos (por gemelación), puede dar lugar a un solo individuo, etc. Esto último se sabrá hacia el día $14{ }^{89}$

Por otro lado, Bascuñán rechaza el argumento de que la continuidad del proceso de desarrollo genere identidad entre distintas partes de ese proceso. ${ }^{90} \mathrm{El}$ mismo autor reconoce que el embrión preimplantacional puede llegar a ser persona, pues todos los seres humanos nacidos vivos fueron embriones preimplantacionales, pero rechaza explí-

${ }^{85}$ Alguien podría cometer el error de pensar que el inciso $1^{\circ}$ del artículo $1^{\circ}$ alude a los no nacidos, al señalar que las personas nacen libres e iguales en dignidad y derechos: si nacen con derechos sería porque los "traen" desde antes de nacer. El error de esta idea consistiría en interpretar la Constitución como si describiera lo que ocurre cuando las personas nacen. Bien sabemos que las normas no describen hechos sino que regulan conductas, de modo que el significado de ese enunciado constitucional es que las personas han de considerarse como titulares de igual dignidad y derechos, quedando constitucionalmente prohibido adoptar decisiones que impliquen lo contrario, desde el momento en que nacen y no después; es decir, no es necesario que hagan nada, ni cumplan cierta edad o adquieran cierta condición para ser titulares de igual dignidad y derechos. Más aún: en la medida en que esta norma prescribe igual y libre trato en dignidad y derechos desde el nacimiento, constituye un ejemplo en contra de la postura mayoritaria, precisamente en la medida en que fija el nacimiento como el hito a partir del cual se es titular de igualdad en dignidad y derechos.

86 Por ejemplo, Vivanco en la obra citada y sobre todo Ugarte, en su libro sobre derecho a la vida.

${ }^{87}$ Como se ha mostrado antes: legítima defensa, pena de muerte según nuestra Constitución, eutanasia en algunos estados, etc.

${ }^{88}$ Revisados los mismos textos de embriología que cita Ugarte, y los que son de habitual circulación, podemos comprobar lo dicho. Ver Langman. Embriología médica, de Sadler, T.W. Editorial Panamericana, 2001; Embriología Humana y biología del desarrollo, de Carlson, Bruce. Editorial Elsevier, 2003; Embriología Clínica, de Moore, Keith, et al., Editorial McGraw-Hill, 1999.

89 Estas disquisiciones llevan a una discusión en la cual los abogados son legos, como si la totipotencialidad implica que no existe todavía un individuo; o si la división gemelar es una forma de reproducción asexuada.

90 Bascuñán, ob. cit., p. 50. 
citamente el argumento de la potencialidad, conforme el cual es persona (en potencia) quien puede llegar a ser persona. ${ }^{91}$ La principal razón de Bascuñán para considerar que el embrión no es persona -y rechazar la postura del magisterio de la Iglesia Católica que él cita- se funda en consideraciones de orden biológico, siguiendo la teoría epigenética sobre el desarrollo del embrión. ${ }^{92}$

Hay que agregar que el argumento escolástico de la potencialidad ha sido rechazado en vasta literatura, como el ejemplo de que una bellota no es un roble aunque pueda llegar a convertirse en él, ${ }^{93}$ o el ejemplo de que el Príncipe Carlos no es el Rey de Inglaterra, aunque pueda llegar a convertirse en él. ${ }^{94}$

1.2. Una segunda idea central de la postura mayoritaria consiste en afirmar que el ser humano desde la concepción es sujeto de protección constitucional y titular del derecho a la vida. Esta segunda idea de la postura mayoritaria significa que el preembrión y un ser humano nacido gozan de la misma protección desde un punto de vista constitucional. Esta tesis se estructura a partir del supuesto de que el embrión fecundado constituye una persona. El fundamento que se indica para esta afirmación es el artículo $19 \mathrm{~N}^{\circ} 1$ inc. $2^{\circ}$. Pues bien, este fundamento es cuestionable por varias consideraciones:

a) Esa norma constitucional no atribuye derechos o titularidad sino que establece un mandato de protección dirigido al legislador. Así lo señala expresamente: la ley protege (entiéndese: debe proteger) la vida del que está por nacer. Por lógica deóntica ${ }^{95}$ sabemos que de un deber de protección no se infieren derechos. Por ejemplo, una norma puede establecer el deber de proteger $\mathrm{X}$ ( $\mathrm{X}$ puede ser un bosque nativo, el medio ambiente en general, una especie, etc.) pero de ahí no se sigue que $\mathrm{X}$ haya sido ungido como titular de derechos; eso significaría que los bosques serían titulares de derechos. Esto ha quedado claro en la jurisprudencia comparada que hemos revisado: las Cortes reconocen deberes de protección sin que eso entrañe derechos para los protegidos.

b) La Constitución ordena proteger la vida, no el derecho a la vida del nasciturus. Proteger la vida no implica proteger el derecho a la vida. Una ley puede prohibir cazar ciertas especies; al hacerlo protege su vida pero no su supuesto derecho a la vida. En el caso del nasciturus, esto ha sido explícito en las sentencias colombianas, que distinguen su vida (que se protege), del derecho a la vida (que no posee).

91 Ibid., pp. 49-50.

92 Ibid., pp. 50-53.

93 Thomson, J.J., "A Defense of Abortion", en Philosophy and Public Affairs, Vol. 1, N 1 (Autumn, 1971), p. 47.

94 Singer, P., Etica Práctica, ob. cit., p. 153. Incluso un metafísico como Sartre rechaza la distinción potencia-acto. Sartre, Jean-Paul, El Ser y la Nada. Traducción de Juan Valmar. Editorial Losada, Séptima Edición, Buenos Aires, 1983, p. 12.

95 “[D]e un derecho subjetivo pueden inferirse normas de deber, pero no a la inversa." Bascuñán, ob. cit., p. 49. 
c) La titularidad del derecho a la vida está expresamente asignada a la persona, como lo indica el artículo 19 en su encabezado en relación con el número 1 inciso. $1^{\circ}$. La sola existencia del inciso $2^{\circ}$ demuestra que el que está por nacer no es titular de derechos. Y ya hemos visto que conforme el Código Civil, personas son aquellos seres humanos que han nacido y sobrevivido un momento siquiera al nacimiento.

d) Cuando la Constitución ordena proporcionar protección al que está por nacer, no establece que esa protección deba comenzar con la concepción. De hecho, no indica cuando debe comenzar. En consecuencia, corresponde al legislador adoptar (o cambiar) una decisión al respecto. La doctrina mayoritaria supone que la protección debe comenzar con la fecundación pero no proporciona ningún argumento para interpretar el artículo $19 \mathrm{~N}^{\circ} 1$ inc. $2^{\circ}$ en ese sentido.

Gómez lo dice del siguiente modo:

"[C]onsiderar al feto como titular del derecho a la vida, desde el instante de la concepción, implica negar toda posibilidad de conflicto, incluso cuando converjan riesgos ciertos y claros para la vida de la madre al continuar el embarazo, cuando importa una ofensa y una indignidad a su condición de ser humano autónomo, y otras hipótesis similares." 96

1.3. Una tercera idea suscrita por de la postura mayoritaria y que es consecuencia de las dos tesis anteriores es que el aborto debe entenderse prohibido siempre. Esta idea supone que proteger la vida y permitir el aborto son actos normativos excluyentes. Esta afirmación puede controvertirse por varias razones:

a) Proteger es un verbo distinto de prohibir. El derecho positivo protege en muchos ámbitos sin recurrir a prohibiciones.

b) Se puede proteger mediante una prohibición sin que sea necesario que tal prohibición sea absoluta. La postura mayoritaria asume dos supuestos: que proteger implica prohibir y que toda prohibición debe ser absoluta. Esto carece de fundamento. Es posible proteger hasta un cierto punto y permitir el aborto también hasta un cierto punto, tal como lo hemos visto en todos los casos de justicia constitucional del derecho comparado. La determinación exacta de la protección corresponde al legislador. Además, debe tenerse en cuenta que si el derecho a la vida de personas (nacidas) no es absoluto, ${ }^{97}$ puesto que la propia Constitución admite la pena de muerte, menos puede serlo la vida de quien no es persona ni titular de derechos. En consecuencia, el inciso $2^{\circ}$ del numeral $1^{\circ}$ del artículo 19 no puede interpretarse como que confiere protección absoluta a la vida del que está por nacer.

96 Gómez, ob. cit., p. 311.

97 Entendiendo aquí por derecho absoluto aquel derecho respecto del cual un titular no pueda ser privado constitucionalmente. Así entendido, el derecho a la vida no es absoluto. Sin embargo, esta forma de entender derecho absoluto tiene poco sentido, como señala Alexy. En cambio, si entendemos por absoluto el que un derecho no pueda ser ponderado ni limitado frente a otros derechos -que sí tiene sentido según ese autor- entonces ningún derecho es absoluto, con lo cual se refuerza nuestro argumento. 
1.4. Una cuarta idea que es posible identificar en la posición mayoritaria consiste en afirmar que "el derecho a la vida" implica el derecho a la "vida".

La mayoría de la doctrina nacional sostiene que "el derecho a la vida" consiste en el derecho a la "vida" entendida como realidad biológica-fenoménica. Esto es lo que lleva a algunos ${ }^{98}$ a hablar de vida digna o de vivir bajo ciertas condiciones, cuando aluden al derecho a la vida. A esa tesis se agrega una lógica naturalista: todo ser que tenga vida tiene derecho a ella. En consecuencia, la tesis queda configurada del siguiente modo: todo ser humano -que tiene vida desde la concepción- tiene derecho a la vida desde la concepción. Es posible dirigir varias objeciones a esta posición:

a) Este entendimiento del derecho a la vida confunde la vida con el derecho a la vida. Ambas cosas son distintas, como también lo son expresarse y el derecho a la libertad de expresión, o la salud y el derecho a la protección de la salud. La jurisprudencia comparada distingue claramente la vida del derecho a la vida, sobre todo el fallo de la Corte colombiana del año 2006. La vida es un fenómeno biológico que existe en individuos particulares por un tiempo efímero; es decir, el ser humano inevitablemente muere, salvo ciertas creencias religiosas. No existe, evidentemente, un derecho a vivir o a estar o a permanecer vivo, por la inevitabilidad de la muerte.

El objeto de un derecho a algo ${ }^{99}$ nunca puede ser una cosa o una conducta de su titular. De ser así, el derecho se estructuraría como una relación diádica que carece de relevancia jurídica. Los derechos suponen relaciones triádicas que involucran la conducta de terceros. Sólo de ese modo un derecho puede tener significado para su titular. ${ }^{100} \mathrm{El}$ objeto de un derecho a algo es la conducta de terceros, que se puede regular en diversos niveles. ${ }^{101}$ En el caso del derecho a la vida, el objeto del derecho consiste -al menos- en

98 Por ejemplo Cea, ob. cit.

99 Usando la terminología de Alexy, los derechos fundamentales comprenden derechos a algo, libertades y competencias. Alexy, R., Teoría de los Derechos Fundamentales. Centro de Estudios Constitucionales. Madrid, 1993.

${ }^{100}$ En esto sigo a Alexy. Una relación diádica significaría que el sujeto titular se relaciona con una cosa. Eso no tiene ningún sentido. Tampoco el titular se relacione con su propia conducta. La relación jurídica que supone un derecho a algo es triádica y se representa como DabG: a es el titular, b es el destinatario, G expresa el objeto del derecho y D simboliza la relación entre esos 3 elementos. El objeto del derecho, G, consiste en la conducta que el destinatario b debe ejecutar. Si G fuera la conducta del titular del derecho, entonces la conducta de b no estaría vinculada por el derecho del titular y eso tornaría en trivial a ese derecho, pues si la conducta del destinatario no estuviera regulada, entonces él podría hacer lo que estimara pertinente, pudiendo bloquear el derecho del titular. En cambio, incorporando a b en la relación, $G$ determina qué conductas puede ejecutar $b$, y eso es lo que le da sentido al derecho de a.

101 Abjorn Eide, a partir de las elaboraciones de Henry Shue, ha identificado tres niveles de obligaciones: a) Obligación primaria de repetar: "The obligation to respect requires the state, and hence all its organs and agents, to abstain from doing anything that violates the integrity of the individual or infringes on her or his freedom, including the freedom to use the material resources available to that individual in the way she or he finds best to satisfy personal basic needs." b) Obligación secundaria de proteger. "The obligation to protect requires form the state and its agents the measures necessary to prevent other individuals or groups from violating the integrity, freedom of action, or other human rights of the individual - including infringement on the enjoyment of her or his materials resources.” c) Obligación terciaria de 
la obligación de no matar arbitrariamente. Sólo porque los demás tienen la obligación de abstenerse de matarme arbitrariamente es que yo puedo intentar disfrutar de mi vida como realidad fenoménica. Por tanto, el derecho a la vida no implica el derecho a vivir ni todo el que tiene vida tiene derecho a la vida.

b) Junto con lo anterior, debe descartarse la suposición naturalista que atribuye titularidad al solo hecho de ser. Como es sabido, no podemos derivar lógicamente un deber ser de un hecho bruto. ${ }^{102,103}$ En consecuencia, desaparece la vinculación necesaria (como pretende ese argumento) entre vida, derecho a la vida $y$ ser humano y se deja espacio para definiciones no necesarias sino jurídico-políticas sobre el derecho a la vida, como son las que han tomado diversos ordenamientos jurídicos, incluyendo el chileno. La titularidad del derecho a la vida es consecuencia de decisiones políticas, como en todos los demás derechos. Los ordenamientos jurídicos confieren derecho a la vida a ciertos titulares, no a todo ser vivo (por lo pronto, a ninguna especie que no sea humana).

1.5. Una quinta idea que aparece en cierta doctrina ${ }^{104}$ consiste en sostener que la Convención Americana confiere titularidad del derecho a la vida al nasciturus y

satisfacer/cumplir. "The obligation to fulfil requires the state to take measures necessary to ensure for each person within its jurisdiction opportunities to obtain satisfaction of those needs, recognized in the human rights instruments, which cannot be secured by personal efforts." En Eide, Absjorn. "National Sovereignty and International Efforts to Realize Human Rights." En Human Rights in Perspective: A Global Assessment. (Eds.) Absjorn Eide \& Berut Hagtvet. Blackwell Publishers. Oxford, 1992, p. 5. Ver también Eide, Asbjorn. "Realization of Social and Economic Rights and the Minimum Threshold Approach." HRLJ vol 10, N. 1-2 (1989), p. 37; Hunt, Paul. Reclaming Social Rights. International and Comparative Perspectives. Dartmounth Publishing Company. USA.1996, pp. 31-33; Puta-Chekwe, Chisanga and Flood, Nora. "From Division to Integration: Economic, Social and Cultural Rights as Basic Human Rights." Giving Meaning to Economic, Social and Cultural Rights. (Eds.) Isfahan Merali and Valerie Oosterveld. Penn. University of Pennsylvania Press. Philadelphia, 2001, p. 43.

102 J. Searle ha tratado de mostrar como es posible derivar debe de es en "How to Derive "Ought" from "Is"”, en The Philosophical Review, LXXIII, 1964. En mi opinión, el intento de Searle no fructifica pues el ejemplo que él utiliza -el acto de prometer-corresponde a un hecho institucional, no a un hecho bruto, y yo entiendo que cuando se plantea la objeción naturalista (construida a partir de un comentario de Hume, David, Tratado sobre la Naturaleza Humana, Editora Nacional, Madrid, 1981, pp. 698-690) se está aludiendo a lo que actualmente llamamos hechos brutos, no bechos institucionales. Por su parte, Thomson \& Thomson también suscriben la opinión de que el intento de Searle es fallido, en James Thomson y Judith Thomson, "How not to Derive "Ought" from Is"”, en The Philosophical Review, Vol. 73, No 4 (Oct., 1964), particularmente p. 516). Sobre la distinción entre hechos brutos e institucionales, Ver Searle, J. Actos de Habla, Planeta-Agostini, Barcelona, 1994, pp. 58 y ss.

103 Curiosamente, Ugarte se refiere al principio de Hume en su libro El derecho a la vida, y lo desacredita en 10 líneas, sin ninguna referencia bibiográfica, creyendo advertir que el mismo Hume se contradijo en el famoso pasaje citado en la nota anterior (ver p. 55). No merece atención este intento de Ugarte, quien por lo demás cuando cita el pasaje de Hume, lo cita así: Tratado del Entendimiento, III, i, 1. Pues bien, Hume no escribió un Tratado sobre el Entendimiento. Ugarte, o se refiere al Tratado sobre la Naturaleza Humana, pero la cita del pasaje is-ought no es III, i, 1, o se refiere a la Investigación sobre el Entendimiento Humano (An Enquiry Concerning Human Understanding), pero en esta obra Hume no alude al problema is-ought.

104 Como Verdugo, Pfeffer, Cea, entre otros. 
que prohíbe el aborto. En un caso se llega al extremo de citar el artículo 4.1 de la Convención Americana eliminando la cláusula "y en general”. ${ }^{105}$

Pues bien, estas ideas deben descartarse. Como sabemos, la Convención reconoce el derecho a la vida y señala que: "Este derecho estará protegido por la ley y, en general, a partir del momento de la concepción.” No es necesario recurrir al caso Baby Boy para advertir que la presencia o ausencia de esta cláusula es un elemento esencial para resolver la titularidad del no nacido. ${ }^{106}$ Así pues, invocar la Convención Americana en este punto constituye un error, ${ }^{107}$ como hemos visto en el caso Babyboy.

1.6. Una sexta idea contenida en la doctrina dominante es que las actas reflejan la intención del constituyente de prohibir el aborto. Esta sugerencia debe desecharse.

a) En primer lugar, recurrir a las actas no es un buen criterio de interpretación constitucional. ${ }^{108}$ b) En segundo lugar, en materia del estatus del nasciturus y la regulación del aborto, las actas van en la dirección contraria de la postura mayoritaria, particularmente en lo referente al significado de la frase "la ley protege la vida del que está por nacer." Ese enunciado expresamente significa -según los redactores- que no se prohíbe el aborto de modo absoluto, sino que se puede permitir en ciertos casos. Sólo a modo de ejemplo:

Ovalle: “....aun cuando no es partidario del aborto, considera que hay determinadas circunstancias que lo justifican, en especial, en todos aquellos casos en que en virtud de un delito -la violación, por ejemplo- una mujer engendre en sus entrañas un hijo no querido por ella y, sobre todo, rechazado por ella. Le parece que, en esas circunstancias, el aborto se justifica plenamente."109

105 Es el caso de Fermandois, ob. cit.

106 Esta tergiversación de la Convención Americana es inexcusable. En las primeras páginas de su artículo, Fermandois distingue los partidarios del constitucionalismo real (entre los cuales él se incluye) de los supuestos seguidores del constitucionalismo hipotético (entre los cuales parece incluir a Bascuñán, A.) y caracteriza al constitucionalismo hipotético por reescribir los términos de la Constitución cuando se estiman negativos, p. 93. Sin reconocer ningún valor a esa distinción ni a la filiación de unos y otros en esas categorías, de todos modos unos se puede preguntar si acaso no está Fermandois haciendo exactamente aquello que denuncia.

107 “...sostener que la Convención Americana obliga al estado a penalizar todo aborto es un error profundo.” Medina, C., La Convención Americana, ob. cit., p. 77.

108 Como se ha sostenido en "De por qué no debemos prestar tanta atención al argumento genético en la interpretación constitucional." Figueroa, R. Revista de Ciencias Sociales. Facultad de Derecho y Ciencias Sociales, Universidad de Valparaíso, Edeval, 2000. Allí se explican argumentos pragmáticos, conceptuales y de principios para no utilizar las actas como criterio de interpretación de la Constitución.

Un autor llega a sostener que es relevante considerar, como elemento histórico, incluso un acuerdo de la Sala del Senado cuando participó en la aprobación de una reforma a la Constitución. Ver Fermandois, ob. cit., p. 101.

109 Sesión 87 a 14 de noviembre de 1974, p. 12. Tomado de las Actas Oficiales de la Comisión de Estudio de la Nueva Constitución. 
Evans: "Estima, en consecuencia, que si se va a consagrar el derecho a la vida, debe consagrarse, también, el derecho a la vida del que está por nacer, pero dejando abierta la posibilidad para que el legislador el día de mañana, según lo requieran las condiciones sociales, pueda, en determinadas circunstancias, proceder con cierta flexibilidad." 110

Silva: "El señor SILVA BASCUÑÁN acota que también existe consenso en no colocar nada relacionado con el aborto."111

Ortúzar: "El señor ORTÚZAR (Presidente) señala que al quedar entregada esta materia al legislador, este determinará en qué caso y en qué forma protegerá la vida del que está por nacer." 112

Evans: "El señor EVANS expresa que piensa como el señor Presidente, pero frente al aborto terapéutico -ya las razones han sido expuestas- cree que el legislador, la ley penal, puede tener una posición de apertura o comprensión muy diferente que respecto del aborto común, como, por ejemplo, en el caso de un padre que, enfrentado al drama horrendo de tener que determinar en un momento dado -en un conflicto que se ha analizado muchas veces- entre la vida de su mujer y de su hijo, escoge la de su mujer y, al respecto, estima que someter, además, a ese padre a proceso, sería excesivo. Añade que él también ha entendido que esa expresión implicaba darle al legislador, en materia penal, la posibilidad de dejar marginado de las figuras constitutivas de delito en esta materia, aquellas que se produjeran o que surgieran con ocasión de una decisión como la que ha señalado."113

Silva: "El señor SILVA BASCUÑ̃́N considera que es un avance del constituyente establecer no sólo el precepto de protección del derecho a la vida, sino también la protección de la vida del que está por nacer, porque eso será un buen argumento para que el legislador no abra la posibilidad a la legalización excesiva del aborto. Estima que es evidente que ahí no hay una prohibición directa y absoluta, pero existe una disposición implícita que se fortalece si acaso se incluye en la Constitución dicha frase, y le parece que queda más sólida la condensación (así está en el original; obviamente se entiende "condenación”) implícita de todo abuso del legislador si se coloca esa frase que si no se incluye. Declara que es partidario de establecer dicha expresión, porque el legislador tendrá, en esta forma, mucha inclinación por sostener esta posición defensiva de la vida del que está por nacer, y por ello es ardiente partidario de mantener la frase en la Constitución." 114

Guzmán: "El señor GUZMÁN hace presente que, en todo caso, desea dejar testimonio de su opinión convencida y contraria al precepto que se ha aprobado, y de

\footnotetext{
110 Sesión $87^{\mathrm{a}}, 14$ de noviembre de 1974 , pp. 14-15.

111 Sesión 90a, 25 de noviembre de 1974, p. 13.

112 Ibid.

113 Ibid., p. 16

114 Ibid., p. 18.
} 
su profundo desencanto de que, en realidad, la Constitución no vaya a tomar una definición en esta materia..."115, 116

Por tanto, de las actas se desprende que había acuerdo sobre no prohibir el aborto y la redacción recogida, tomada del Código Civil, claramente no lo prohíbe, como dejó de manifiesto Jaime Guzmán -antes citado-, quien se opuso a esa redacción e incluso más tarde intentó que se cambiara. En general, los comisionados consideraron que la ley debía proteger la vida del nasciturus. Esto significa que la regla general no es matar la nasciturus sino protegerla, pero implica entonces que en ciertos casos sí se puede permitir el aborto, a discreción del legislador, como varios comisionados señalaron de modo explícito, incluyendo Silva Bascuñán. Esta es, por lo demás, la situación imperante en casi toda la jurisprudencia constitucional existente en la materia, exceptuando el caso de EE.UU. que es mucho más permisiva. Es decir, los comisionados tuvieron sobre el aborto la misma visión que recoge casi toda la jurisprudencia comparada e internacional.

Para cerrar esta sección de comentarios sobre la doctrina nacional dominante, cabe decir que desde el punto de vista del derecho positivo y de la interpretación que mejor concuerda con él, la posición canónica sobre la idea de persona humana, que se advierte en la mayoría de la doctrina nacional, carece de sustento constitucional.

\section{Comentarios sobre la jurisprudencia nacional}

En esta materia existe sólo un fallo claramente explícito sobre el tema de la titularidad del derecho a la vida, que es el fallo de la Corte Suprema del 2001. Este fallo no puede estimarse una buena guía.

En primer lugar, se trata de una sentencia dictada en una acción de protección. Este tipo de jurisdicción es de urgencia, cautelar, no corresponde a una sede en la cual se puedan debatir problemas constitucionales de fondo, como sí lo es el caso de la Corte federal estadounidense, la alemana, la española o la colombiana. Por tanto, no debiéramos sacar conclusiones apresuradas. Importante sería una sentencia del Tribunal Constitucional chileno, que no es una jurisdicción cautelar.

En segundo lugar, el fallo fue 3 votos contra a 2, es decir, se acordó por el mínimo y nunca más se ha reiterado.

En tercer lugar, y entrando en el contenido de la sentencia, se puede apreciar que ella adolece de incoherencia: Declaró en el $\mathrm{C}^{\mathrm{o}} 15$ que el ser humano tiene derecho a la vida, lo que no es trivial pues el artículo 19 de la Constitución habla de personas, no de seres humanos. Este $\mathrm{C}^{\circ}$ podría hacernos pensar que la Corte lisa y llanamente está haciendo sinónimos ser humano y persona, pero no es así, como se ve en el $\mathrm{C}^{\circ} 17$. Luego, la Corte dijo que “...se hace evidente que el que está por nacer (...) tiene derecho a la vida, es decir, tiene derecho a nacer y a constituirse en persona con todos los atributos

115 Ibid., p. 20.

116 En cuanto a la sesión 407, ver el texto de Bascuñán, ob. cit. 
que el ordenamiento jurídico le reconoce...”, desde que el óvulo es fecundado hasta el nacimiento $\left(\mathrm{C}^{\circ} 18\right)$. Al decir que el nasciturus tiene derecho a la vida (en el $\mathrm{C}^{\circ} 15$ había dicho que el ser humano tiene derecho a la vida) y que tiene derecho a constituirse en persona, está reconociendo que el nasciturus no es persona, ${ }^{117}$ sino que será persona en el futuro. Esto es importante. La Corte no está haciendo sinónimos persona y el que está por nacer. Pero, si no es persona, no puede tener derecho a la vida según el artículo 19, que asigna titularidad a las personas. Si la Corte declara en el $\mathrm{C}^{\circ} 17$ que el nasciturus no es persona pero sí tiene derecho a la vida, está alterando la titularidad del derecho indicada en el encabezado del artículo 19. Y no esgrime ningún antecedente para ello. Sin embargo, aquí no terminan los problemas, pues en el $C^{\circ} 18$ la Corte se remite al artículo 55 del Código Civil, que define quiénes son personas (todos los seres humanos, cualquiera sea su edad $)^{118}$ y a los artículos 75 y 76 , que la Corte emplea para reconocer protección constitucional al nasciturus. ¿Qué está sucediendo exactamente? Que la Corte está declarando en el $\mathrm{C}^{\circ} 18$ que el nasciturus es persona para efectos constitucionales, contradiciendo ${ }^{119}$ lo que dijo el $\mathrm{C}^{\mathrm{o}} 17$. Por tanto no debiéramos considerar especialmente relevante este fallo por ser incoherente y carecer de fundamento.

\section{Sintesis de la jurisprudencia comparada e internacional}

En esta parte, más que comentarios se realiza una síntesis de la jurisprudencia comparada e internacional.

a) Salvo el caso de Alemania, la titularidad del derecho a la vida se concede a los seres humanos que han nacido. En efecto, en los casos de EE.UU. y Colombia sólo son titulares las personas (y se entiende por tales los nacidos) y en el caso de España son titulares "todos", que también se entiende que han nacido. b) Lo anterior no implica que el nasciturus carezca de protección constitucional. Al contrario, en todos los casos se ha declarado que el estado debe proteger la vida en gestación. c) Al mismo tiempo, en todos los casos se ha reconocido que una prohibición absoluta del aborto es inconstitucional porque anula los derechos de la mujer. Incluso en Alemania, que reconoce al nasciturus como titular del derecho a la vida, ese derecho se pondera y cede en ciertos casos ante los derechos de la mujer. d) Por tanto, proteger al nasciturus y permitir el aborto en ciertos casos se considera no sólo como algo compatible sino como un resultado obligado a partir de la ponderación de intereses y derechos constitucionalmente protegidos.

Esta doctrina parece razonable. Una prohibición absoluta del aborto instrumentaliza a la mujer, reduciéndola -como señaló la Corte Colombiana- “...a un mero receptáculo

$117 \mathrm{Ni}$ siquiera que es persona en potencia, de modo que la Corte no acoge la tesis de la potencialidad.

118 Resulta sorprendente que la Corte sólo se cite los artículos 55, 75 y 76 y omita el artículo 74 del Código Civil, según el cual la persona existe legalmente desde el nacimiento.

119 La misma opinión manifiesta Bascuñán, ob. cit., p. 48. 
de la vida en gestación, carente de derechos o de intereses constitucionalmente relevantes que ameriten protección." 120

Estas consideraciones debieran servir para la discusión en Chile, en que parece haber dos posturas algo extremas. En un extremo están quienes sostienen que el nasciturus no es persona porque no ha nacido y por ello carece de protección constitucional, de modo que el legislador podría regular el aborto sin restricciones constitucionales. En el otro extremo se encuentran quienes consideran que el nasciturus es persona titular del derecho a la vida desde la fecundación y, por ello, el aborto debe prohibirse de manera absoluta siempre. A partir de lo que hemos visto en la jurisprudencia comparada, se desprenden dos cosas: 1 . Sea o no persona el nasciturus, y tenga o no derecho a la vida, de todos modos debe protegerse. En ningún caso se puede estimar que el nasciturus es una "cosa" u "objeto" carente de relevancia constitucional. 2. El aborto nunca puede prohibirse de modo absoluto porque existen casos en los cuales la carga del embarazo no es exigible a la mujer (Alemania, Colombia) y/o porque una prohibición absoluta lesiona derechos de la mujer (EE.UU., Colombia, España).

\section{BIBLIOGRAFÍA}

Actas Oficiales de la Comisión de Estudios de la Nueva Constitución.

Alexy, R., Teoría de los Derechos Fundamentales. Centro de Estudios Constitucionales. Madrid, 1993.

Bascuñán, A., "La píldora del día después ante la jurisprudencia”. Estudios Públicos, Centro de Estudios Públicos, 95, Santiago (invierno 2004).

Carlson, B., Embriología Humana y biología del desarrollo, Editorial Elsevier, 2003.

Carrasco, S., "La garantía constitucional del derecho a la vida del que está por nacer". XVIII Jornadas Chilenas de Derecho Público. Universidad de Concepción, Concepción, 1987.

Catecismo de la IGlesia Católica. Ediciones Trípode. Segunda edición. Caracas, 1993.

CEA, José L., Derecho Constitucional Chileno, Tomo II, Ediciones Universidad Católica de Chile, Santiago, 2004.

Corral, H., "El concepto jurídico de persona. Una propuesta de reconstrucción unitaria". Revista Chilena de Derecho, Vol. 17 (1990).

Corral, H., "Admisibilidad jurídica de las técnicas de procreación artificial". Revista Chilena de Derecho, Vol. 19, $\mathrm{N}^{\circ} 3$ (1992).

EIDE, A., "Realization of Social and Economic Rights and the Minimum Threshold Approach". En HRLJ vol 10, No 1-2 (1989).

EIDE, A., "National Sovereignty and International Efforts to Realize Human Rights." En Human Rights in Perspective: A Global Assessment. (Eds.) Absjorn Eide \& Berut Hagtvet. Blackwell Publishers. Oxford, 1992.

Evans, E., Los Derechos Constitucionales, Tomo I, Editorial Jurídica de Chile, $3^{\text {a }}$ edición, Santiago, 2004. 
Fermandois, A., "La píldora del día después: aspectos normativos". Estudios Públicos, 95 (invierno), Santiago, 2004.

Finmma, G., "El Derecho a la vida. Antecedentes en las Actas de la Comisión de Estudios Constitucionales”. En Revista de Derecho Público, No 27 (enero-junio), 1980.

Figueroa, G., Persona, pareja y familia, Editorial Jurídica de Chile, Santiago, 1995.

Figueroa, G., Derecho Civil de la Persona Humana, Editorial Jurídica de Chile, Santiago, 2001.

Figueroa, R., "De por qué no debemos prestar tanta atención al argumento genético en la interpretación constitucional”. En Revista de Ciencias Sociales, Facultad de Derecho y Ciencias Sociales, Universidad de Valparaíso, Edeval, 2000.

Gómez, G., Derechos Fundamentales y Recurso de Protección, Ediciones Universidad Diego Portales, Santiago, 2005.

Hume, D., Tratado sobre la Naturaleza Humana, Editora Nacional, Madrid, 1981.

Hunt, P., Reclaming Social Rights. International and Comparative Perspectives. Dartmounth Publishing Company. USA.1996.

Nogueira, H., "El derecho a la vida en el ordenamiento jurídico chileno". Gaceta Jurídica, $\mathrm{N}^{\circ} 207,1997$.

Medina, C., La Convención Americana: Teoría y Jurisprudencia. Centro de Derechos Humanos, Facultad de Derecho, Universidad de Chile, Santiago, 2003.

Moore, K. et al., Embriología Clínica. Editorial McGraw-Hill, 1999.

Precht, J., "Consideraciones ético-jurídicas sobre el aborto terapéutico". Revista Chilena de Derecho, Vol. 19 (1992).

Puta-Chekwe, Ch. y Flood, N., "From Division to Integration: Economic, Social and Cultural Rights as Basic Human Rights". En Giving Meaning to Economic, Social and Cultural Rights. (Eds.) Isfahan Merali y Valerie Oosterveld. Penn. University of Pennsylvania Press. Philadelphia, 2001.

SAdler, T.W., Embriología médica, Editorial Panamericana, 2001.

Sartre, J.-P., El Ser y la Nada. Traducción de Juan Valmar. Editorial Losada, Séptima Edición, Buenos Aires, 1983.

Searle, J., "How to Derive "Ought" from "Is"”, The Philosophical Review, LXXIII, 1964.

Searle, J., Actos de Habla, Planeta-Agostini, Barcelona, 1994.

SIlva, J., "El nasciturus y el derecho a la vida", Revista de Derecho Público, Nos. 57/58, enero-diciembre. Santiago, 1995.

Singer, P., Ética Práctica, Traducción de Marta Guastavino, Ariel, 2a edición, Barcelona, 1988.

Soто, E., "Derecho a la vida y recurso de protección", Revista de Derecho y Jurisprudencia y Gaceta de los Tribunales, Tomo LXXXI, No 2, mayo-agosto, Santiago, 1984, Primera Parte.

Soto, E., "El derecho a la vida y la noción de persona en la Constitución". Revista de Derecho y Jurisprudencia y Gaceta de los Tribunales. Tomo LXXXVIII, No 3, 1991, Primera parte.

Soto, E., "La noción de persona en la Constitución", Revista de Derecho Público, No 50 , juliodiciembre, Santiago, 1991.

Thomson, J., “A Defense of Abortion”, en Philosophy and Public Affairs, Vol. 1, No 1 (Autumn, 1971).

Thomson, J. y Thomson, J., "How not to Derive “Ought” from Is"”, en The Philosophical Review, Vol. 73, No 4 (oct., 1964).

Ugarte, J. J., "Momento en que el embrión es persona humana". Estudios Públicos, 96 (primavera), Santiago, 2004.

Ugarte, J. J., El Derecho de la vida. El derecho a la vida, bioética y derecho, Editorial Jurídica de Chile, Santiago, 2006. 
Varela, J., “Derechos Humanos y Aborto”, Revista de Derecho Público, Nos. 47/48, enero-diciembre, Santiago, 1990.

Verdugo, M., Pfeffer, E., Nogueira, H., Derecho Constitucional. Editorial Jurídica de Chile. Segunda Edición, Santiago, 2005.

Vivanco, A., Curso de Derecho Constitucional. Ediciones Universidad Católica de Chile. Santiago, 2006.

Zapata, P., "Persona y embrión humano. Nuevo problemas legales y su solución en el derecho chileno". Revista Chilena de Derecho, Vol. 15, No 3 (1988). 